TFBP-TR-275

for U.S. Nuclear Regulatory Commission

\title{
REACTIVITY INITIATED ACCIDENT TEST SERIES RIA SCOPING TEST EXPERIMENT PREDICTIONS
}

\author{
R.S. SEMKEN \\ A.M. EATON \\ R.H. SMITH \\ S.C. RESCH
}

June 1978
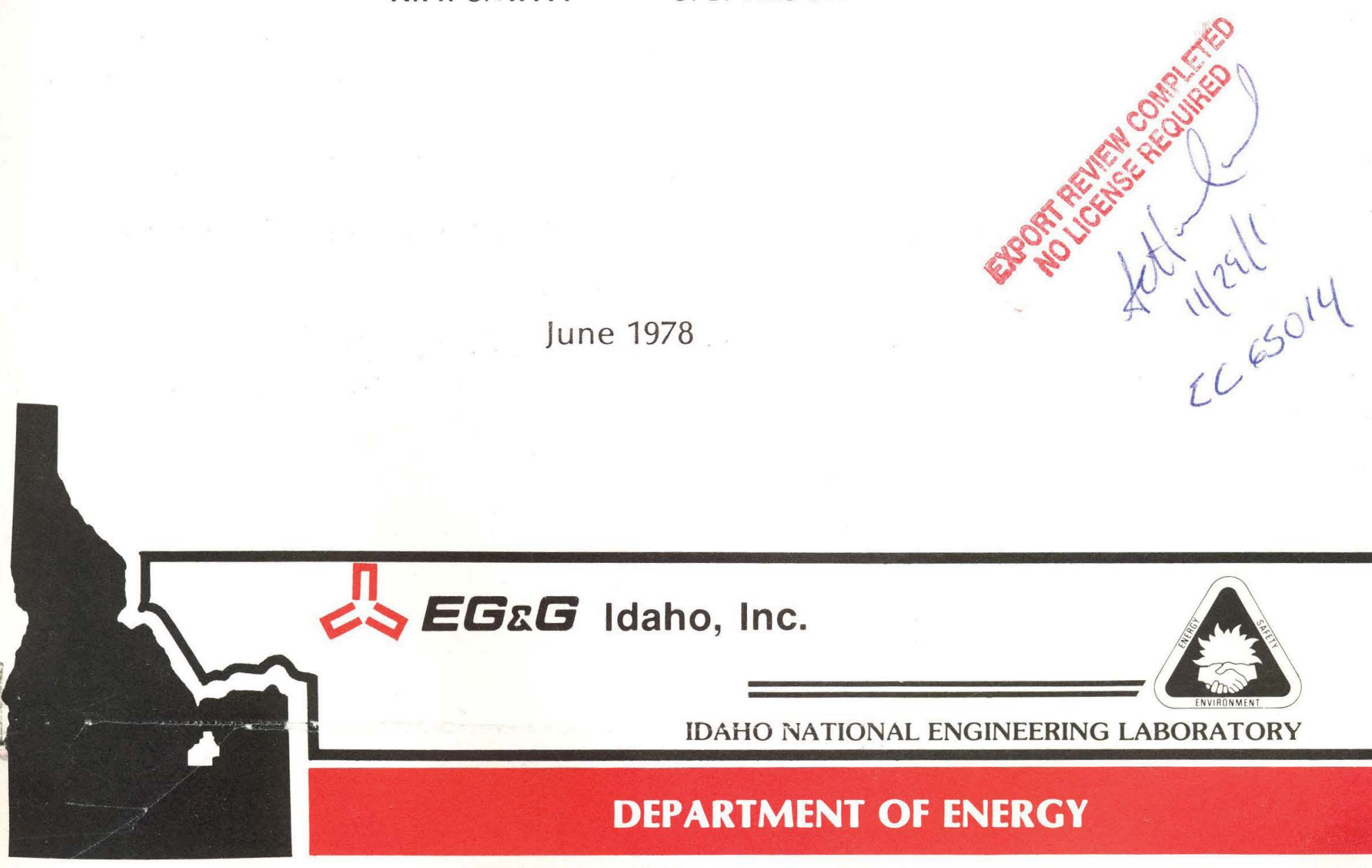

EG\&G Idaho, Inc.

IDAHO NATIONAL ENGINEERING LABORATORY

\section{DEPARTMENT OF ENERGY}


TFBP-TR-275

for U.S. Nuclear Regulatory Commission

\title{
REACTIVITY INITIATED ACCIDENT TEST SERIES RIA SCOPING TEST EXPERIMENT PREDICTIONS
}

\author{
R.S. SEMKEN \\ A.M. EATON \\ R.H. SMITH \\ S.C. RESCH
}

June 1978

\section{EG\&G Idaho, Inc.}

\section{DEPARTMENT OF ENERGY}


TFBP-TR-275

June 1978

\section{REACTIVITY INITIATED ACCIDENT TEST SERIES SCOPING TEST EXPERIMENT PREDICTIONS}
R. S. Semken
A. M. Eaton
R. H. Smith
S. C. Resch

Approved:

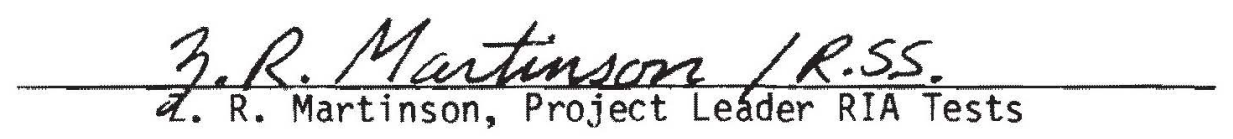

A.5. Mehner/RKM

A. S. Mehner, Supervisor

PCM, RIA, IE, and Gap Conductance Tests Section

\section{R.K. MeCancel}

R. K. McCarde 11, Acting Manager

Experiment Specification and Analysis Branch

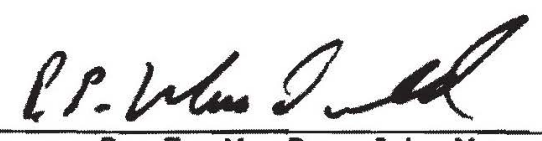

P. E. MacDonald, Manager

Thermal Fuels Behavior Division 


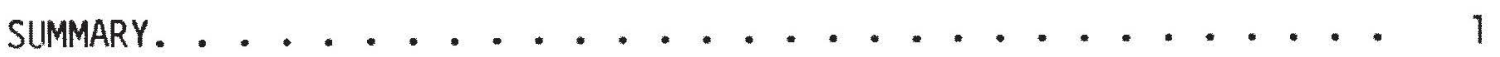

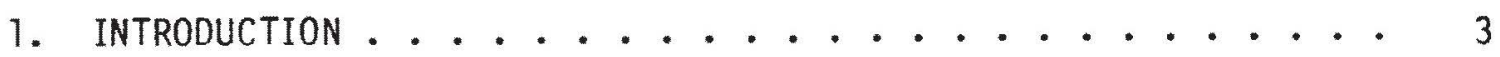

2. TeSt design and Planned conduct. . . . . . . . . 5

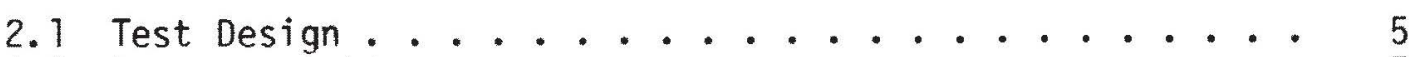

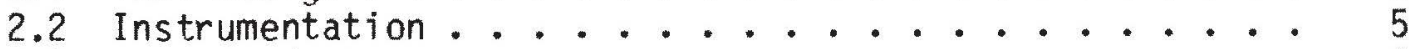

2.3 Test Conduct. ................. 8

3. TEST PREDICTION ANALYSES .................... 10

3.1 Reactor Physics Analysis............ 10

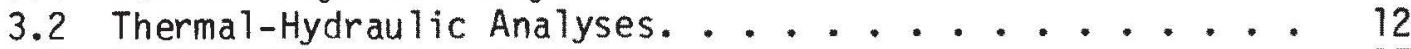

3.3 Fuel Rod Behavior Analyses............ 17

3.4 Cladding Embrittlement Analyses ........... 32

3.5 Pressure Pulse Analyses ............. 36

4. RESULTS OF PREVIOUS RIA TESTS. . . . . . . . . 37

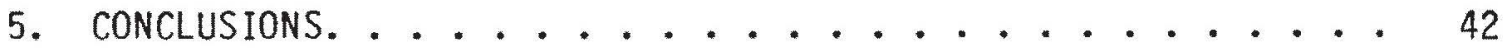

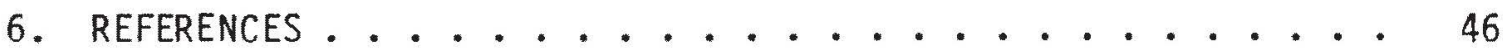

APPENDIX A: RELAP4 MODEL DESCRIPTION ........... 47

APPENDIX B: FRAP-T4 CODE INPUT SUMMARY ......... 53

FIGURES

1. PBF $3.5 \mathrm{~ms}$ period power and energy histories (normalized to

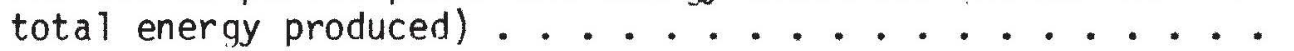

2. Inlet coolant mass flowrate history for a $1350 \mathrm{~J} / \mathrm{g}$ pellet surface energy deposition. . . . . . . . . . .

3. Outlet coolant mass flowrate history for a $1350 \mathrm{~J} / \mathrm{g}$ pellet

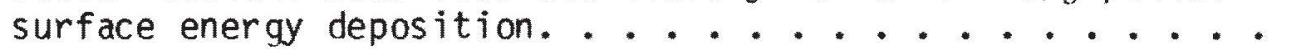

4. Coolant qualities at the axial power peak and flow shroud outlet for a $1350 \mathrm{~J} / \mathrm{g}$ pellet surface energy deposition . . . 16

5. Coolant temperature history at the axial power peak location for a $1350 \mathrm{~J} / \mathrm{g}$ pellet surface energy deposition. . . . . .

6. Fuel rod temperature histories at the axial power peak location for an $815 \mathrm{~J} / \mathrm{g}$ pellet surface energy deposition... 
7. Axial fuel centerline, fuel surface, and cladding surface temperature profiles at the time of the maximum cladding surface temperature for an $815 \mathrm{~J} / \mathrm{g}$ pellet surface energy

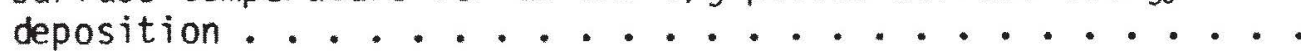

8. Fuel rod gap width history at the axial power peak location for an $815 \mathrm{~J} / \mathrm{g}$ pellet surface energy deposition. . . . . . .

9. Fuel stack and cladding axial elongation histories for an $815 \mathrm{~J} / \mathrm{g}$ pellet surface energy deposition. ........

10. Fuel rod temperature histories at the axial power peak location for a $1020 \mathrm{~J} / \mathrm{g}$ pellet surface energy deposition . . .

11. Axial fuel centerline, fuel surface, and cladding surface temperature profiles at the time of the maximum cladding surface temperature for a $1020 \mathrm{~J} / \mathrm{g}$ pellet surface energy deposition. . . . . . . . . . . . . .

12. Fuel rod gap width history at the axial power peak location for a $1020 \mathrm{~J} / \mathrm{g}$ pellet surface energy deposition. . . . . .

13. Fuel stack and cladding axial elongation histories for a $1020 \mathrm{~J} / \mathrm{g}$ pellet surface enerqy deposition. . . . . . .

14. Fuel rod temperature histories at the axial power peak location for a $1225 \mathrm{~J} / \mathrm{g}$ pellet surface energy

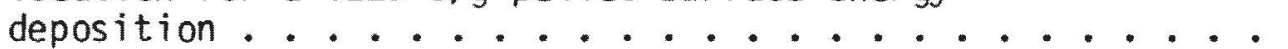

15. Axial fuel centerline, fuel surface, and cladding surface temperature profiles at the time of the maximum $c l a d d i n g$ surface temperature for a $1225 \mathrm{~J} / \mathrm{g}$ pellet surface energy

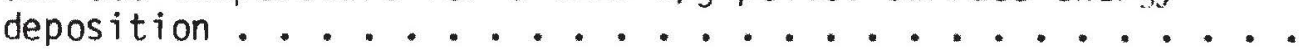

16. Fuel rod gap width history at the axial power peak location for a $1225 \mathrm{~J} / \mathrm{g}$ pellet surface energy deposition. . . . . .

17. Fuel stack and cladding axial elongation histories for a $1225 \mathrm{~J} / \mathrm{g}$ pellet surface energy deposition. . . . . . . . .

18. Radial temperature profiles of fuel at time corresponding to peak centerline temperature for pellet surface energy

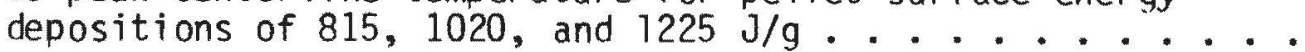

19. Peak cladding temperature as a function of pellet surface

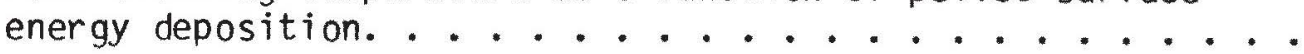

20. Fraction of the original cladding thickness that has remained in the beta-zircaloy phase with respect to pellet surface

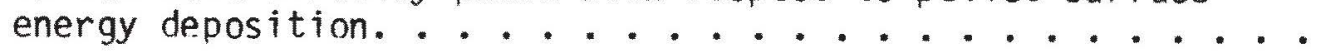



21. Failure behavior of CDC and NSRR Test Fuel rods as a function of pellet surface energy deposition per unit fuel volume...

22. Maximum cladding temperature as a function of pellet surface energy deposition per unit fuel volume for the CDC tests...

TABLES

I. RIA Scoping Test Fuel Rod Design Characteristics. . . . 6

II. RIA Scoping Test Plan ................ 9

III. Energy Deposition in $9.70 \mathrm{~mm}$ OD Test Fuel Rod . . . . . 11

IV. Reaction Layer Cladding Failure Criteria Results for 815, 1020, and $1225 \mathrm{~J} / \mathrm{g}$ Pellet Surface Energy

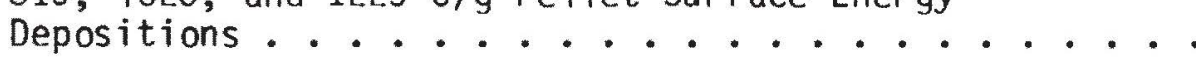



SUMMARY

The Reactivity Initiated Accident (RIA) test series to be conducted in the Power Burst Facility (PBF) has been designed to determine fuel failure thresholds, modes, and consequences as a function of energy deposition, irradiation history, and fuel design. The RIA Scoping Test will be comprised of five single unirradiated rod sub-tests. The first rod will be subjected to a series of transient power bursts of increasing energy release to determine the energy deposition at cladding failure. The second and third rods will be subjected to energy depositions near that which caused failure of the first rod, to further define the failure threshold. Rods four and five will be subjected to large radially averaged enerqy depositions, 1990 and $2510 \mathrm{~J} / \mathrm{g}$ respectively, to investigate facility safety concerns.

Several analyses were performed to predict test fuel rod and system behavior during the five RIA Scoping Test phases. A reactor physics analysis was performed to obtain the relationship between test fuel rod and reactor core energy during a power transient. The calculations were made with the RAFFLE computer code. The thermal-hydraulic behavior of the test rod coolant was investigated for pellet surface energy depositions of 900,1125 , and $1350 \mathrm{~J} / \mathrm{g}$ for the first three phases of the Scoping Test. The RELAP4 computer code was used for these thermalhydraulic analyses. The results of the RELAP4 calculations provided input to the FRAP-T4 computer code for three fuel rod behavior analyses at pellet surface energy depositions of 815,1020 , and $1225 \mathrm{~J} / \mathrm{g}$. A cladding embrittlement analysis, using the results of the FRAP-T4 calculations as input, was made to investigate the cladding oxidation mode of rod failure for the lower energy phases. BUILD5 was the analvtical tool used in this investigation. Finally, the pressure pulses generated as a result of failure of the test fuel rods in the final two high eneray test phases were calculated using the SPIRT computer code.

In previous reactivity initiated accident tests performed in the SPERT, TREAT, and NSRR facilities a pellet surface energy deposition of 
$12.350 \times 10^{3} \mathrm{~J} / \mathrm{cm}^{3}$ was identified as the failure threshold for unirradiated fuel rods with the ambient test conditions of $300 \mathrm{~K}, 0.1 \mathrm{MPa}$, and no forced flow. This volumetric energy deposition is equivalent to a pellet surface energy deposition of $1190 \mathrm{~J} / \mathrm{g}(284 \mathrm{cal} / \mathrm{g})$ when the RIA-ST fuel pellet density of $10.365 \mathrm{~g} / \mathrm{cm}^{3}$ is considered. For no-flow conditions, it was further observed that the presence of a flow shroud caused a reduction of up to $10 \%$ in the failure threshold. The modes of failure seen in the previous tests were cladding embrittlement and low pressure rupture as the zircaloy melting temperature was approached. In general, the rod failures occurred only when a peak cladding temperature of $2073 \mathrm{~K}$ or above was reached.

Based on the analyses, it is predicted that the test fuel rod energy deposition failure threshold will be $1035 \mathrm{~J} / \mathrm{g}(247 \mathrm{cal} / \mathrm{g})$ at the pellet surface for the fuel rods used in the initial three phases of the RIA Scoping Test. The initial coolant conditions for these cases are equivalent to a fuel enthalpy of $69 \mathrm{~J} / \mathrm{g}(16.5 \mathrm{cal} / \mathrm{g})$ at the fuel surface over ambient conditions. When the difference in initial coolant conditions is considered, the total fuel enthalpy increase leading to cladding failure observed in the previous RIA tests is equivalent to $1122 \mathrm{~J} / \mathrm{g}$ $(268 \mathrm{cal} / \mathrm{g})$ at the fuel pellet surface. The difference between the predicted failure threshold value and that observed in previous tests $(87 \mathrm{~J} / \mathrm{g})$ is believed to be a combined result of the presence of a flow shroud and uncertainies in the computer codes used to make the predictions. The mode of failure according to the analyses will be rupture due to high temperature cladding weakening. The consequences of these failures are predicted to he minimal. The mode of failure for the high eneray phases of the Scoping Test will be cladding rupture due to internal rod pressurization from $\mathrm{UO}_{2}$ vaporization. The high energy rod failures were predicted by the SPIRT code to result in source pressure pulses of 24.1 and $24.8 \mathrm{MPa}$ for the 1990 and $2510 \mathrm{~J} / \mathrm{g}$ energy depositions, respectively. Pressure doubling will occur in each case with a rise time of $7 \mathrm{~ms}$ resulting in maximum pressures of 31.7 and $34.5 \mathrm{MPa}$, respectively. 


\section{INTRODUCTION}

The Reactivity Initiated Accident Scoping Test (RIA-ST) will investigate the consequences of fue 1 rod failure during RIA testing in the Power Burst Facility (PBF) at the Idaho National Engineering Laboratory. The test will consist of five subtest phases, each phase beginning with a new single fuel rod. The first three phases, designated RIA-ST-1, RIA-ST-2, and RIA-ST-3, are designed to (a) provide data on the energy deposition threshold beyond which fuel rod failure occurs and (b) develop calorimetric techniques of determining rod power during a transient. The final phases, RIA-ST-4 and RIA-ST-5, are not programmatic tests but were designed to identify the magnitude of pressure pulses expected as a result of large energy depositions $[\mathrm{a}]$.

This Experiment Predictions report addresses three aspects of the RIA Scoping Test. First, the fuel rod energy as a function of PBF reactor core energy for the fue 1 rod configuration used in the first three test phases is predicted based on reactor physics code calculations. Second, the failure energy deposition threshold and the mode of failure are predicted for the first three test phases based on the results of thermal-hydraulic and fuel rod behavior code analyses, cladding embrittlement analysis, and the experimental baseline data obtained from RIA tests conducted in the SPERT, TREAT, and NSRR facilities. Finally, the mode of failure for the two high energy phases, RIA-ST-4 and RIA-ST-5, and the resulting pressure pulses are predicted based on additional fuel rod behavior analysis and SPIRT $[\mathrm{b}]$ computer code analyses.

[a] PBF operator or system errors could produce radially averaged test rod energy depositions as high as $2510 \mathrm{~J} / \mathrm{g}$ while performing a planned $1255 \mathrm{~J} / \mathrm{g}$ four-rod RIA test.

[b] SPIRT: Stress-strain from Pressures Instigated by Reactor Iransients, Configuration Control Number P031101. 
Section 2 of this report briefly describes the test design and planned conduct for the RIA Scoping Test. The respective analyses performed for the experiment predictions are described in Section 3. Section 4 describes the relevant results of the previous RIA tests performed in the SPERT, TREAT, and NSRR facilities, and in Section 5 the conclusions are presented. 


\section{TEST DESIGN AND PLANNED CONDUCT}

This section of the report contains a brief description of the design and an outline of the conduct for the RIA Scoping Test. A more detailed account $c$ an be found in the RIA-ST Experiment Operating Specification [1].

\subsection{Test Design}

The RIA Scoping Test is comprised of five separate, single-rod test phases. The rod for each phase will be positioned in a separate flow shroud in the center of the PBF in-pile tube (IPT). The design of the fuel rods, test assembly, and instrumentation associated with each component are described in the following paragraphs.

The five fuel rods for the RIA Scoping Test phases are designated as $800-1,800-2,800-3,800-4$, and 800-5, respectively. The nominal design characteristics of these rods are given in Table 1 . The fuel rods were fabricated from unirradiated cladding and fresh fuel pellets. The fuel pellets for Rods $800-1,800-2$, and $800-3$ were ground down to fit in available cladding.

Individual zircaloy-4 flow shrouds, having a nominal inner diameter of $16.30 \mathrm{~mm}$ and an outer diameter of $22.6 \mathrm{~mm}$, surround each rod. Fuel particle catch screens are installed at the inlet and outlet of the flow shroud for Rods $800-4$ and $800-5$ only.

The PBF single rod test train assembly will be used for the RIA Scoping Test. In the test assembly, the fuel rod is held rigidly at the top, with the rod free to expand axially downward.

\subsection{Instrumentation}

The instrumentation in the test is provided for pressure pulse measurement, calorimetric measurement of the test rod power, and evaluation 


\section{TABLE I}

RIA SCOPING TEST FUEL ROD DESIGN CHARACTERISTICS

\begin{tabular}{|c|c|c|}
\hline Characteristic & Rods $800-1,2,3$ & Rods $800-4,5$ \\
\hline $\begin{array}{l}\text { Material } \\
\text { Pellet oD (mm) } \\
\text { Pellet length (mm) } \\
\text { Pellet enrichment (\%) } \\
\text { Density ( } \% \text { TD) } \\
\text { Fuel stack length (m) } \\
\text { End configuration } \\
\text { Burnup }\end{array}$ & $\begin{array}{l}\mathrm{UO}_{2} \\
8.23+0.0127 \\
15.2 \\
5.8 \\
94.5 \\
0.914 \\
\text { Dished } \\
\quad 0\end{array}$ & $\begin{array}{l}\mathrm{UO}_{2} \\
9.3+0.0127 \\
15.49 \\
20 \\
93 \\
0.914 \\
\text { Dished } \\
\quad 0\end{array}$ \\
\hline $\begin{array}{l}\text { Cladding } \\
\text { Material } \\
\text { Tube OD }(\mathrm{mm}) \\
\text { Tube wall thickness }(\mathrm{mm})\end{array}$ & $\begin{array}{l}Z r-4 \\
9.70 \\
0.64\end{array}$ & $\begin{array}{l}\mathrm{Zr}-4 \\
10.73 \\
0.61\end{array}$ \\
\hline $\begin{array}{l}\text { Fuel Rod } \\
\text { Overall length (m) } \\
\text { Filler Gas } \\
\text { Initial gas pressure (MPa) }\end{array}$ & $\begin{array}{l}1.0 \\
\text { Helium } \\
0.103\end{array}$ & $\begin{array}{l}1.0 \\
\text { Helium } \\
2.6\end{array}$ \\
\hline
\end{tabular}


of instrumentation to be used in future RIA tests. No instrumentation will be installed on the test fuel rods. A linear variable differential transformer (LVDT), mounted on the test train, will measure cladding elongation for phases RIA-ST-1, RIA-ST-2, and RIA-ST-3.

The test assembly instrumentation consists of the following:

(1) Three coolant pressure transducers, two located above the flow shroud outlet, and one located below the fuel rod to measure the transient pressure response and normal system pressure.

(2) Two turbine flowmeters, mounted in series at the inlet of the flow shroud, to measure the coolant flow through the shroud.

(3) Four thermocouples, two mounted on the shroud inlet and two at the outlet, to measure the coolant temperature at inlet and outlet.

(4) Two differential thermocouples mounted on the test train to measure the coolant temperature rise across the flow shroud.

(5) Three cobalt self-powered neutron detectors (SPND) located in one vertical column at $0.229,0.457$ and $0.686 \mathrm{~m}$ above the bottom of the test fue 1 rod.

(6) One flux wire mounted on the outer surface of the flow shroud for each phase of the test.

(7) Five pressure transducers located in the flow bypass region for radiation sensitivity evaluation.

(8) One linear variable differential transformer (LVDT) mounted at the bottom of the fuel rod to measure changes in axial length of the fuel rod. The LVDT will be removed for RIA-ST-4 and RIA-ST-5 to allow a more precise measurement of the expected pressure pulse. 
(9) Another LVDT, with its core locked in position, located below the fuel rod for radiation sensitivity evaluation.

\subsection{Test Conduct}

The five test phases of the RIA Scoping Test will be designated as RIA-ST-1 through RIA-ST-5. Table II summarizes the various activities associated with the five test phases. Details of the test conduct are discussed in the following paragraphs. Nuclear operation will start after loop heatup and terminate immediately after each transient.

There will be a power calibration for test phases RIA-ST-1, RIA-ST-4, and RIA-ST-5. The objective of the power calibrations will be to intercalibrate the thermal-hydraulically determined fuel power with reactor power and the self-powered neutron detector (SPND) output. The on-line power calibration will be accomplished by measuring the coolant pressure, coolant inlet temperature, coolant temperature rise, and coolant flow. An axial peak-to-average neutron flux ratio of 1.36 will be used for preliminary calculations. The coolant conditions during the power calibration will be $538 \mathrm{~K}, 6.45 \mathrm{MPa}$, and $760 \mathrm{~cm}^{3} / \mathrm{s}$ at the test train inlet. The fuel rod peak power will not exceed $52 \mathrm{~kW} / \mathrm{m}$ during the power calibration.

RIA-ST-1 will include a fuel rod preconditioning phase to build up the fission product inventory of the fuel rod and to cause fuel pellet cracking. The preconditioning will be performed at a fuel rod peak power of $52 \mathrm{~kW} / \mathrm{m}$. The coolant conditions will be $538 \mathrm{~K}, 6.45 \mathrm{MPa}$, and $760 \mathrm{~cm}^{3} / \mathrm{s}$ at the test train inlet.

The test train inlet coolant conditions for each power transient will be $538 \mathrm{~K}, 6.45 \mathrm{MPa}$, and $85 \mathrm{~cm}^{3} / \mathrm{s}$. The reactor transient period for each phase of the test will be chosen on the basis of the RIA Scoping Test power calibration results and PBF lead rod test data. 
TABLE II

RIA SCOPING TEST PLAN[D]

\begin{tabular}{|c|c|c|c|c|}
\hline RIA-ST-1 & RIA-ST-2 & RIA-5T-3 & RIA-ST -4 & RIA-ST-5 \\
\hline Heat Un & Heat Up & Heat up & Heat in & Heat its \\
\hline $\begin{array}{l}\text { Power } \\
\text { calibration }\end{array}$ & $\begin{array}{l}\text { Single } \\
\text { transient } \\
\text { at failure }\end{array}$ & $\begin{array}{l}\text { Sinale } \\
\text { transient } \\
\text { at } 5 T-1 \text { failure }\end{array}$ & $\begin{array}{l}\text { Power } \\
\text { calibration }\end{array}$ & $\begin{array}{l}\text { Power } \\
\text { calithration }\end{array}$ \\
\hline Shut rown & energy. & $\begin{array}{l}\text { energy minus } \\
210 \mathrm{~J} / \mathrm{g} \text { if } \\
\text { rod fails in }\end{array}$ & Shut down & Shutdown \\
\hline $\begin{array}{l}\text { Core flux } \\
\text { wire change }\end{array}$ & Cooldown & $\begin{array}{l}\text { ST }-2 \text {; single } \\
\text { transient, at } \\
\text { ST-1 fatlure }\end{array}$ & $\begin{array}{l}\text { Core flux } \\
\text { wire change } \\
\text { single }\end{array}$ & $\begin{array}{l}\text { Core flux } \\
\text { wire change } \\
\text { single. }\end{array}$ \\
\hline $\begin{array}{l}\text { Fuel rnd } \\
\text { precon- } \\
\text { ditioning }\end{array}$ & & $\begin{array}{l}\text { energy plus } \\
210 \mathrm{~J} / \mathrm{g} \text { if } \\
\text { rod roes not }\end{array}$ & $\begin{array}{l}\text { transient at } \\
1090 \mathrm{~J} / \mathrm{g}\end{array}$ & $\begin{array}{l}\text { transient at } \\
2510 \mathrm{~J} / \mathrm{g}\end{array}$ \\
\hline Shut rown & & fâl in $S T-2$. & Coolriown & Cooldown \\
\hline $\begin{array}{l}\text { Core flux } \\
\text { wire change }\end{array}$ & & Cooldown & & \\
\hline \multicolumn{5}{|c|}{$\begin{array}{l}835 \mathrm{~J} / \mathrm{q}(900 \mathrm{~J} / \mathrm{q} \text { pellet surface) } \\
\text { transient }\end{array}$} \\
\hline \multicolumn{5}{|l|}{ Shut down } \\
\hline \multicolumn{5}{|l|}{$\begin{array}{l}\text { Core flux } \\
\text { wire change }\end{array}$} \\
\hline \multicolumn{5}{|c|}{$\begin{array}{l}1045 \mathrm{~J} / \mathrm{g}(1125 \mathrm{~J} / \mathrm{g} \text { pellet surface) } \\
\text { transient }\end{array}$} \\
\hline \multicolumn{5}{|l|}{ Shutdown } \\
\hline \multicolumn{5}{|l|}{$\begin{array}{l}\text { Core flux } \\
\text { wire change }\end{array}$} \\
\hline \multicolumn{5}{|c|}{$\begin{array}{l}1140 \mathrm{~J} / 9(1240 \mathrm{~J} / \mathrm{q} \text { pellet surface) } \\
\text { transient }\end{array}$} \\
\hline \multicolumn{5}{|l|}{ Shutrown } \\
\hline \multicolumn{5}{|l|}{$\begin{array}{l}\text { Core fiux } \\
\text { wire change }\end{array}$} \\
\hline \multicolumn{5}{|c|}{$\begin{array}{l}1255 \mathrm{~J} / \mathrm{g}(1350 \mathrm{~J} / \mathrm{g} \text { pellet surface }) \\
\text { transient }\end{array}$} \\
\hline \multicolumn{5}{|l|}{$\begin{array}{l}\text { Continued } \\
\text { unt il ron } \\
\text { failure }\end{array}$} \\
\hline Cooldown & & & & \\
\hline
\end{tabular}

[a] Unless otherwise noter, all energy renosition valuac are radially averanod enerqies deposited at the axial prwar pajk mpantion. 


\section{TEST PREDICTION ANALYSIS}

A discussion of the analyses performed for the test predictions and a presentation of the results are contained in this section. The reactor physics analys is is discussed first, followed by the thermal-hydraulic analyses, fuel rod behavior analyses, cladding embrittlement analysis, and finally the pressure pulse analyses.

\subsection{Reactor Physics Analys is}

The reactor physics calculations were done to predict fuel rod energy as a function of PBF reactor core energy for Rods 800-1, 800-2, and $800-3$. These are the $9.70 \mathrm{~mm}$ oD fuel rods to be used in the three initial test phases.

The reactor physics calculations [2] were performed by the EG\&G Reactor Physics Engineering Branch using the SCAMP Sn-transport theory code $[a, 3]$. The amount of energy deposited into the test rod and PBF driver core was calculated using the factors of $178.2 \mathrm{MeV} /$ fission for the test fuel and $186.4 \mathrm{MeV} / \mathrm{fission}$ for the driver core. These values include no contribution from delayed gammas or betas, since more than 99\% of the energy deposition due to these components does not occur until after the completion of the transient.

The radial power profile calculated for the $9.70 \mathrm{~mm}$ OD fuel rods by the SCAMP code is shown in Table III. The radial peak-to-average power ratio is 1.076 with the peak located at the pellet surface.

[a] SCAMP, Configuration Control Number H00029IB. ENDF/B-II, -III, -IV Library, Configuration Control Number H00170IB. 
TABLE III

ENERGY DEPOSITION IN $9.70 \mathrm{~mm}$ OD TEST FUEL ROD

\begin{tabular}{cccc}
\hline Region & Outer Radius & Axial Average & Axial Peak \\
& $(\mathrm{mm})$ & Energy $[\mathrm{a}]$ & Energy $[\mathrm{a}]$
\end{tabular}

$\begin{array}{cccc}1 & 1.84 & 2.897 & 3.940 \\ 2 & 2.60 & 2.977 & 4.049 \\ 3 & 3.19 & 3.065 & 4.168 \\ 4 & 3.68 & 3.169 & 4.310 \\ 5 & 4.12 & \underline{3.320} & \underline{4.515} \\ \text { Average } & & 3.086 & 4.197\end{array}$

[a] Joules absorbed per gram of $\mathrm{UO}_{2}$ in the test rod for each megawat-t-second of energy deposited in the PBF driver core. The axial peak was assumen to be 1.36 times the axial average. 


\subsection{Thermal-Hydraulic Analyses}

Three thermal-hydraulic analyses were made with $\operatorname{RELAP} 4[a, 4]$ to provide data on the IPT coolant behavior during three RIA power transients. These data were used as coolant boundary conditions for three fuel rod behavior analyses. A RELAP4 transient model of the PBF in-pile tube was developed and is described in Appendix A.

The three analyses considered axial power peak energy depositions of 900 , 1125, and $1350 \mathrm{~J} / \mathrm{g}(215,270$, and $325 \mathrm{cal} / \mathrm{g})$ at the pellet surface of the fuel of the $9.70 \mathrm{~mm}$ OD fuel rods. The normalized power and energy histories used for each analysis are shown in Figure 1. These curves are based on a PBF reactor period power transient of $3.5 \mathrm{~ms}$. Scaling factors were applied to the normalized power and energy histories to achieve the desired energy depositions in the RELAP4 calculations. The calculations were run for $29 \mathrm{~s}$ following the initiation of each power transient at $1.0 \mathrm{~s}$.

The initial test train inlet coolant conditions assumed in the analyses were $538 \mathrm{~K}, 6.45 \mathrm{MPa}$, and $495 \mathrm{~kg} / \mathrm{m}^{2} \cdot \mathrm{s}\left(285 \mathrm{~cm}^{3} / \mathrm{s}\right)$. The magnitude of the inlet pressure necessitated the use of an interpolation between the Barnett and modified Barnett critical heat flux (CHF) correlations. The Groeneveld 5.7 film boiling correlation was used for post-CHF calculations.

The results of the RELAP4 analysis describing the coolant behavior for the $1350 \mathrm{~J} / \mathrm{g}$ energy deposition are illustrated by Figures 2 through 5. Since the results of the 900 and $1125 \mathrm{~J} / \mathrm{g}$ deposition calculations were similar to those for the $1350 \mathrm{~J} / \mathrm{g}$ case, they are discussed only briefly.

Figures 2 and 3 describe the coolant flow shroud inlet and outlet mass flow rates, respectively, as a function of time. At approximately

[a] RELAP/MOD5, Configuration Control Number H00330IB. 
$\vec{\omega}$

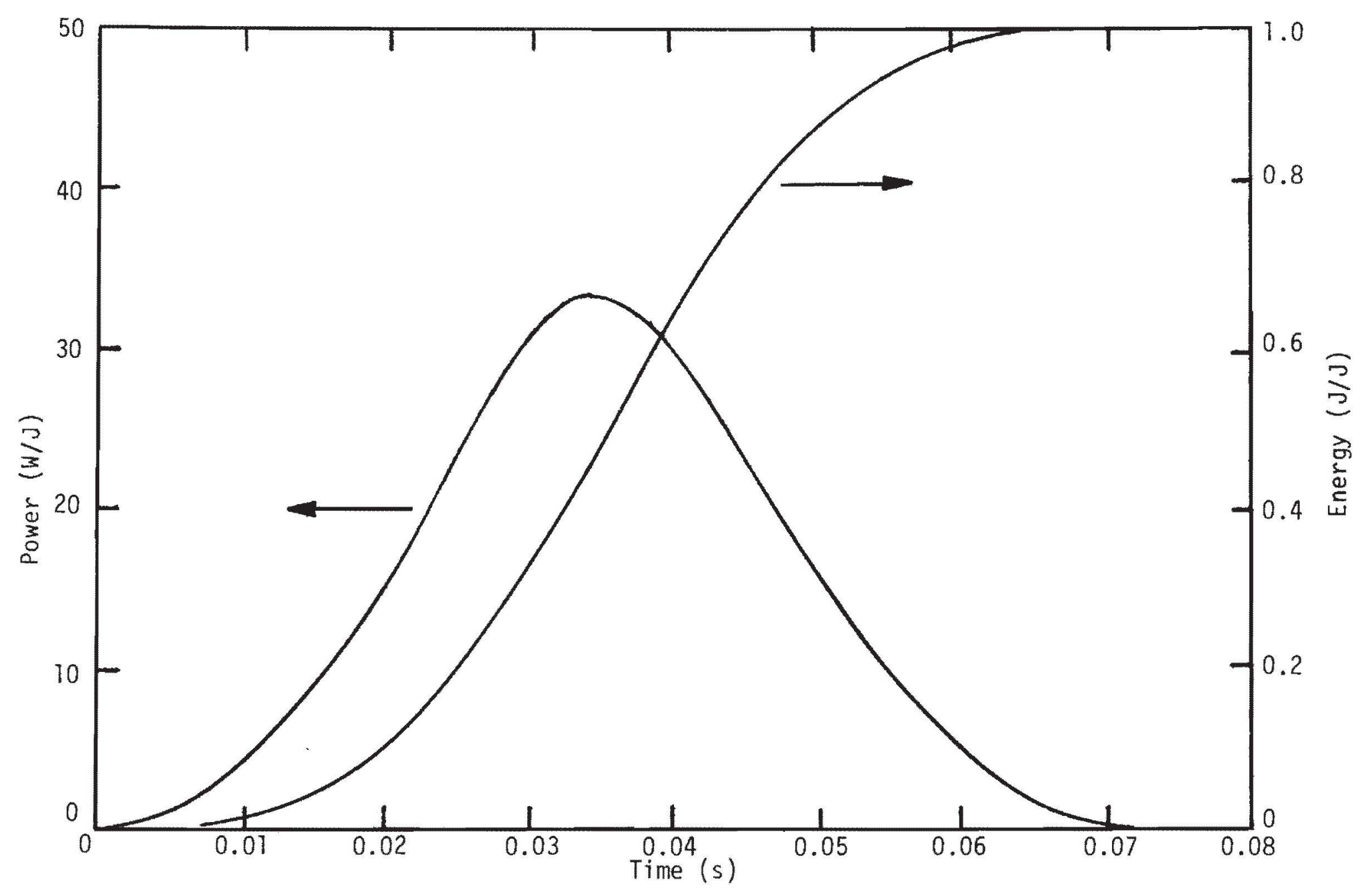

Fig. I PBF $3.5 \mathrm{~ms}$ period power and energy histories (normalized to total energy produced). 


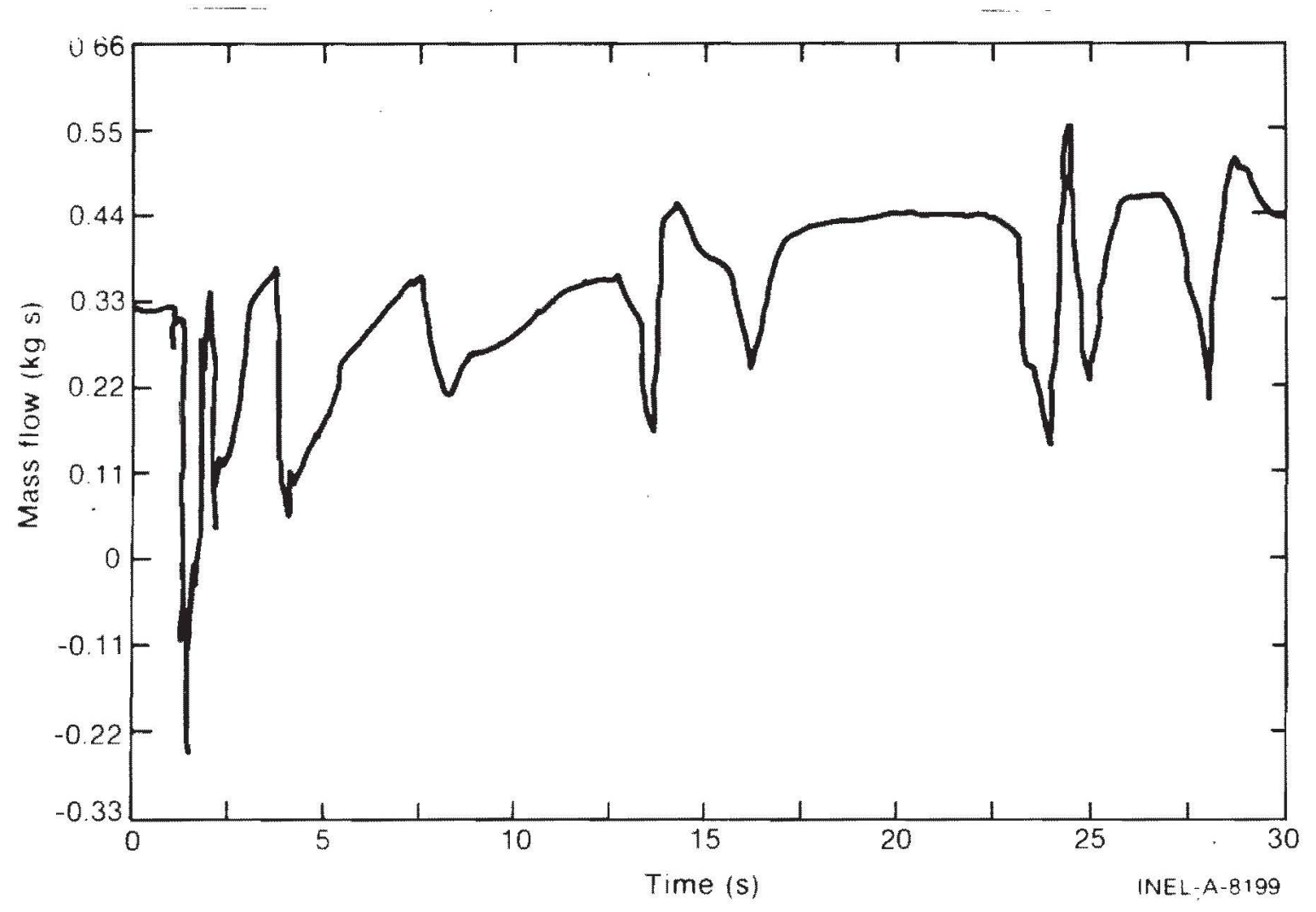

Fig. 2 Inlet coolant mass flowrate history for a $1350 \mathrm{~J} / \mathrm{g}$ pellet surface energy deposition.

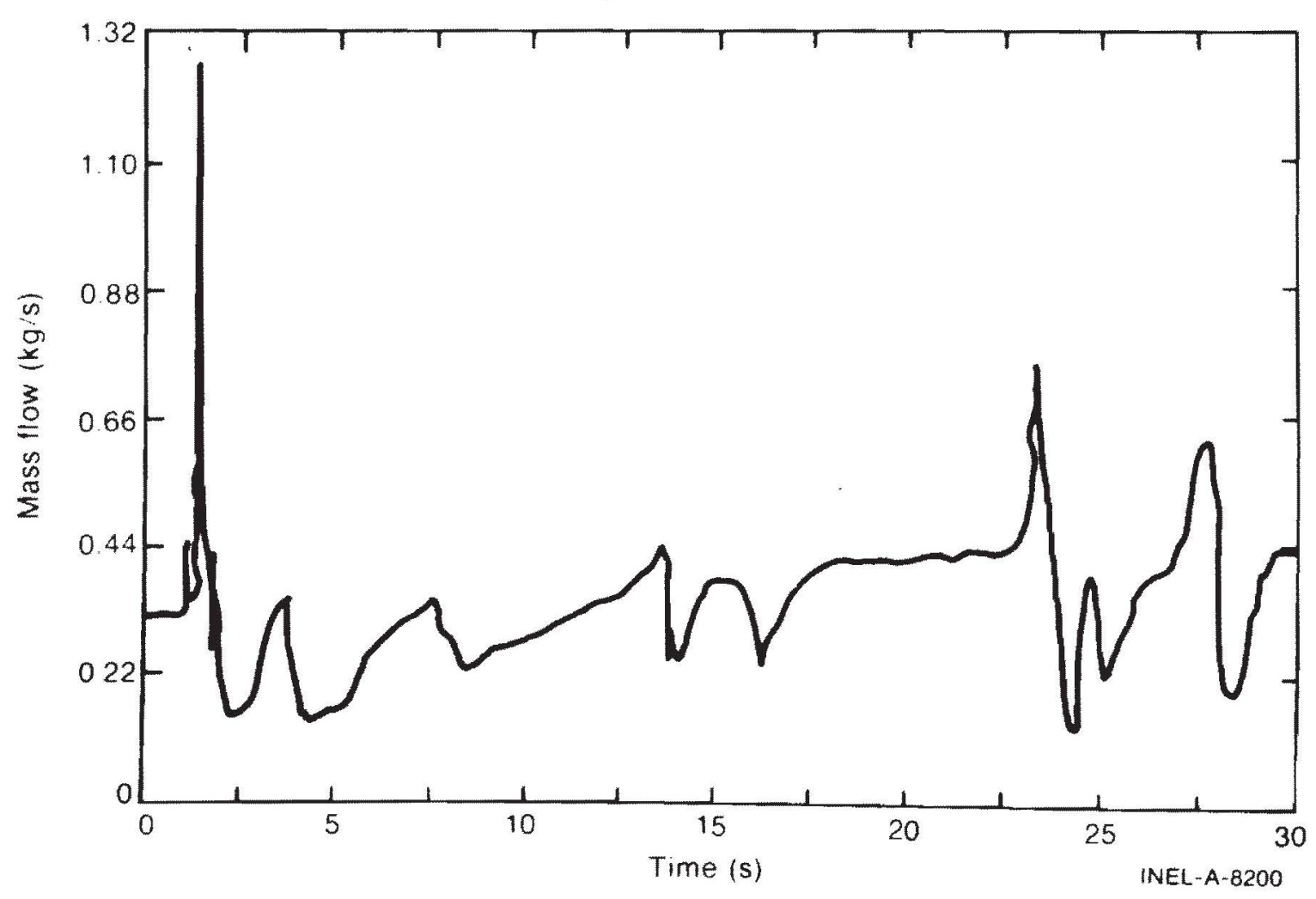

Fir. 3 Outlet coolant mass flowrate history for a $1350 \mathrm{~J} / \mathrm{g}$ pellet surface energy deposition. 
$0.5 \mathrm{~s}$ after the transient initiation, a flow reversal at the coolant inlet with a peak mass flowrate of $-0.25 \mathrm{~kg} / \mathrm{s}$ and a flow surge at the coolant outlet with a peak magnitude of $1.27 \mathrm{~kg} / \mathrm{s}$ are indicated. This is due to initial coolant vaporization and subsequent rapid flow shroud voiding. Positive flow at the coolant inlet is reestablished a short time thereafter. After the resumption of positive flow, Figures 2 and 3 indicate that the coolant inlet and outlet flows oscillate. These oscillations are believed to be due to thermal changes occurring in RELAP4 at this stage of the analysis, in particular, changes in heat transfer mode and coolant quality.

Figure 4 illustrates the coolant quality as a function of time at the axial hot spot and coolant outlet locations. Peak qualities of 16 and $36 \%$ are indicated for the two locations, respectively. The peaks occur about $1.5 \mathrm{~s}$ after transient initiation. The sporadic increases in quality, which are indicated by Figure 4 during the decline in quality, occur in response to heat transfer mode changes within the RELAP4 calculational mechanism. Coolant quality at the hot spot reached zero after about $25 \mathrm{~s}$.

Figure 5 illustrates the coolant temperature at the axial hot spot as a function of time. The temperature is shown to reach saturation $(552.5 \mathrm{~K})$ almost immediately. At about $22 \mathrm{~s}$ the brief drop in temperature indicates a temporary resumption of single phase flow and then, because of quality increases upstream, a jump back to two phase flow with an accompanying increase in quality (Figure 4).

The results of the RELAP4 calculations for a $900 \mathrm{~J} / \mathrm{g}$ energy deposition also indicated a flow reversal at the shroud inlet and a flow surge at the outlet. The flow reversal and surae were shown to peak at $-0.025 \mathrm{~kg} / \mathrm{s}$ and $0.18 \mathrm{~kg} / \mathrm{s}$, respectively. Positive flow was resumed at the inlet within $1.0 \mathrm{~s}$. Coolant quality at the axial hot spot peaked at. about 9\% approximately $2 \mathrm{~s}$ after transient initiation. It reached zero at about $14 \mathrm{~s}$. Coolant quality at the shroud out let peaked at $13 \%$ almost $8 \mathrm{~s}$ after the transient. It returned to zero at about $24 \mathrm{~s}$. coolant temperature at the axial hot spot increased to saturation within $0.3 \mathrm{~s}$ of 


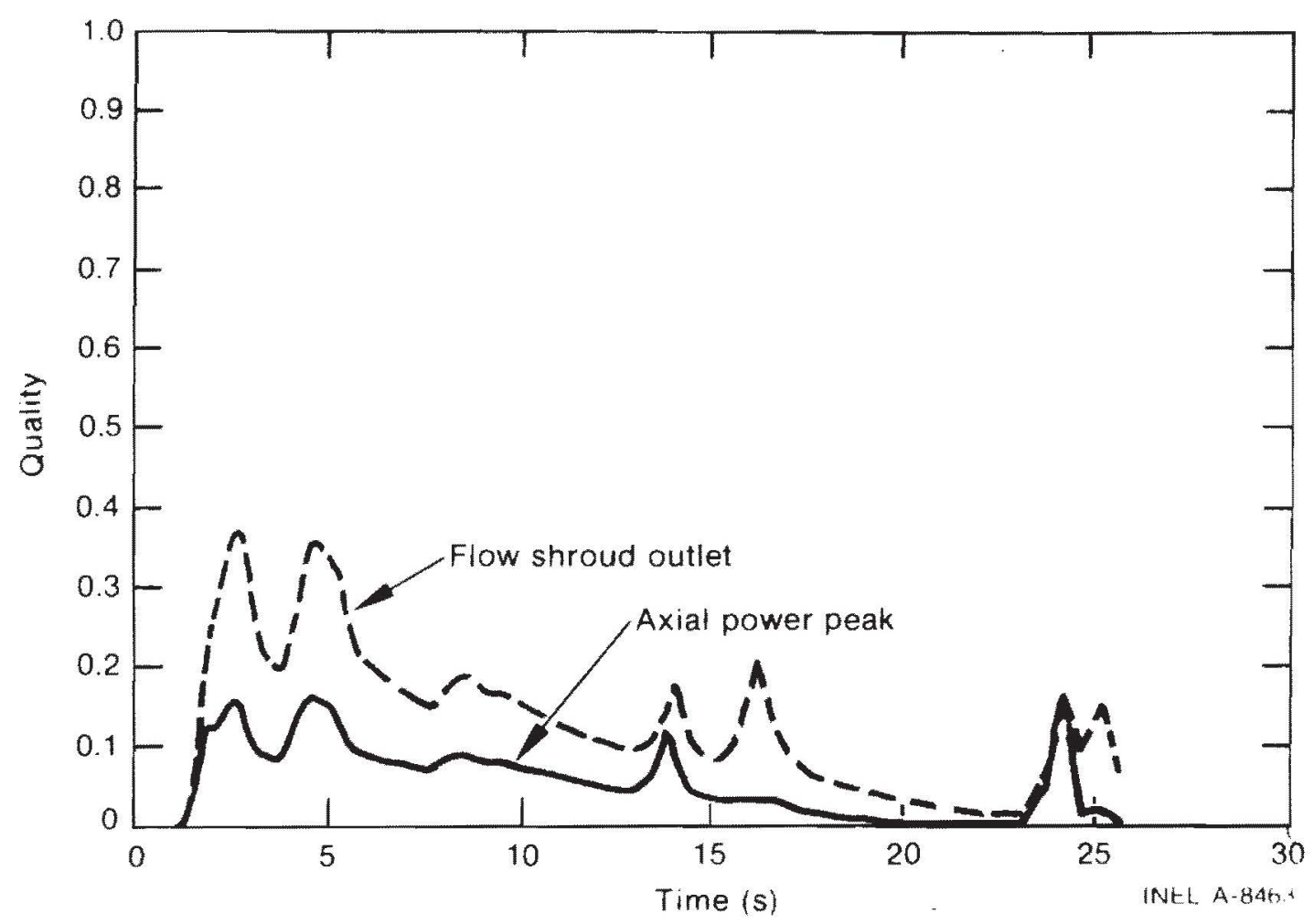

Fi,. I Coolant qualities at the axfal power peak and flow shroud outlet for a 135 ? $\mathrm{J} / \mathrm{c}$ pellet surface energy deposition,

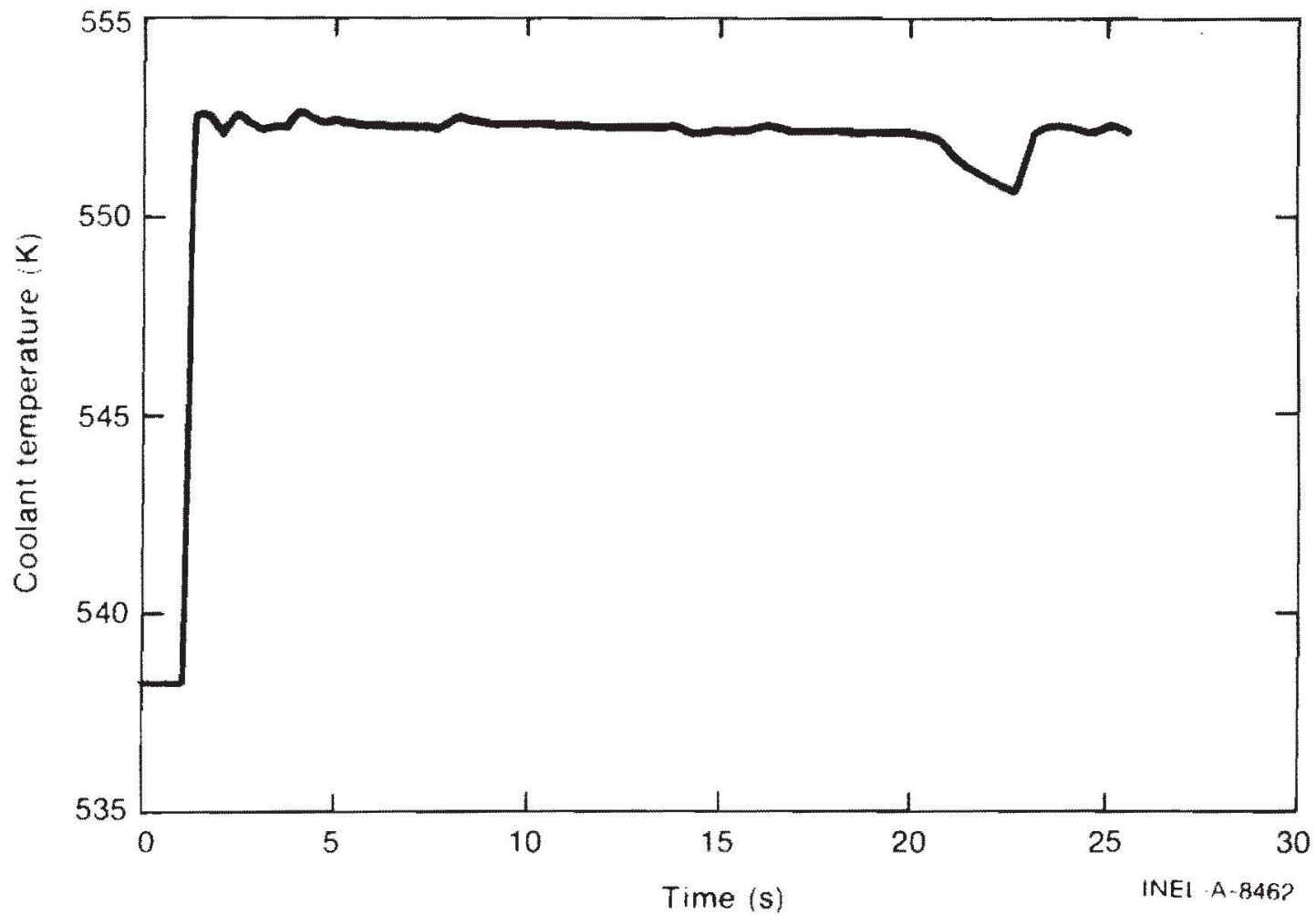

Fig. 5 Coolant temperature history at the axial power peak location for a $1350 \mathrm{~J} / \mathrm{g}$ pellet surface energy deposition. 
transient initiation and remained near this temperature for the next $21.5 \mathrm{~s}$ after which it began decreasing to the initial coolant temperature.

The results of the $1125 \mathrm{~J} / \mathrm{g}$ deposition calculations indicated a flow reversal and flow surge peaking at $-0.045 \mathrm{~kg} / \mathrm{s}$ and $0.20 \mathrm{~kg} / \mathrm{s}$. Positive flow conditions were reestablished within $1 \mathrm{~s}$. Coolant quality was shown to reach $15 \%$ at the hot spot almost $4 \mathrm{~s}$ after transient initiation and to decline to zero at $17.5 \mathrm{~s}$. After a $1 \mathrm{~s}$ delay, the quality at the flow shroud outlet ramped up to a peak value of $22 \%$, reaching it 4.5 s after transient initiation. It then declined to zero within $27 \mathrm{~s}$ from the time of transient initiation. Coolant temperature reached saturation within $0.2 \mathrm{~s}$ and remained close to saturation for almost $25 \mathrm{~s}$. The temperature then began falling rapidly back to the initial condition temperature.

\subsection{Fuel Rod Behavior Analyses}

The analytical model used for the fuel rod thermal and mechanical behavior analyses was the Fuel Rod Analys is Program - Transient Version 4 (FRAP-T4) computer code $[\mathrm{a}, 5]$. FRAP-T4 is a general purpose code designed to analyze the behavior of nuclear fuel rods subjected to transient conditions. The behavior of a rod is predicted by using an iterative solution technique that combines and couples the effects of thermal, mechanical, and material properties. FRAP-T4 prediction analyses were made to provide data on the energy deposition failure threshold for the following cases:

(1) a $9.70 \mathrm{~mm}$ OD fuel rod with a pellet surface, axial peak eneray deposition of $815 \mathrm{~J} / \mathrm{g}(195 \mathrm{cal} / \mathrm{g})$,

(2) a $9.70 \mathrm{~mm}$ oD fuel rod with a pellet surface, axial peak energy deposition of $950 \mathrm{~J} / \mathrm{g}(245 \mathrm{cal} / \mathrm{g})$,

[a] FRAP-T4, Version 9/16, Configuration Control Number H003251B 
(3) a $9.70 \mathrm{~mm}$ OD fuel rod with a pellet surface, axial peak energy deposition of $1225 \mathrm{~J} / \mathrm{g}(295 \mathrm{cal} / \mathrm{g})$, and

(4) a $10.73 \mathrm{~mm}$ OD fuel rod with a radially averaged, axial peak enerqy deposition of $2510 \mathrm{~J} / \mathrm{g}(600 \mathrm{cal} / \mathrm{g})$.

The coolant conditions (pressure, temperature, enthalpy, and mass flux) calculated by the three RELAP4 models discussed in Section 3.2 were used as the input coolant boundary conditions for the three $9.70 \mathrm{~mm}$ OD fuel rod behavior calculations. The small differences in the energy depositions between the RELAP4 and FRAP-T4 calculations will not create significant errors. The coolant conditions for the $10.73 \mathrm{~mm}$ OD fuel rod calculations were idealized by inputting to the coolant an estimate of the axially averaged enthalpy resulting from the $2510 \mathrm{~J} / \mathrm{g}$ power transient [a].

The FRAP-T4 model used 18 equi-spaced axial nodes for calculational purposes with heat transfer correlations identical to those used in the RELAP4 analyses. The same power-time history that was used in the RELAP4 analyses (Figure 1) was also used for these FRAP-T4 analyses. Calculations for cases 1,2, and 3 were continued for more than $25 \mathrm{~s}$ in each case after the start of the power transient. At this time the entire fuel rod length had quenched in each case. For case 4 , the calculations were discontinued after $I \mathrm{~s}$ because rod failure was indicated. A summary of the FRAP-T4 input for the four cases is given in Appendix B.

\subsubsection{FRAP-T4 Calculations for a Pellet Surface Energy Deposition} of $815 \mathrm{~J} / \mathrm{g}$. The results of the FRAP-T4 calculations for a pellet surface energy deposition of $815 \mathrm{~J} / \mathrm{g}$ are illustrated by Figures 6 through 9 . For this case, the power transient was started at $1.0 \mathrm{~s}$, and the calculations were continued for $29 \mathrm{~s}$.

[a] This idealization is possible because, due to the extremely rapid rod failure, there is little time for the rod behavior to be influenced by coolant conditions. 


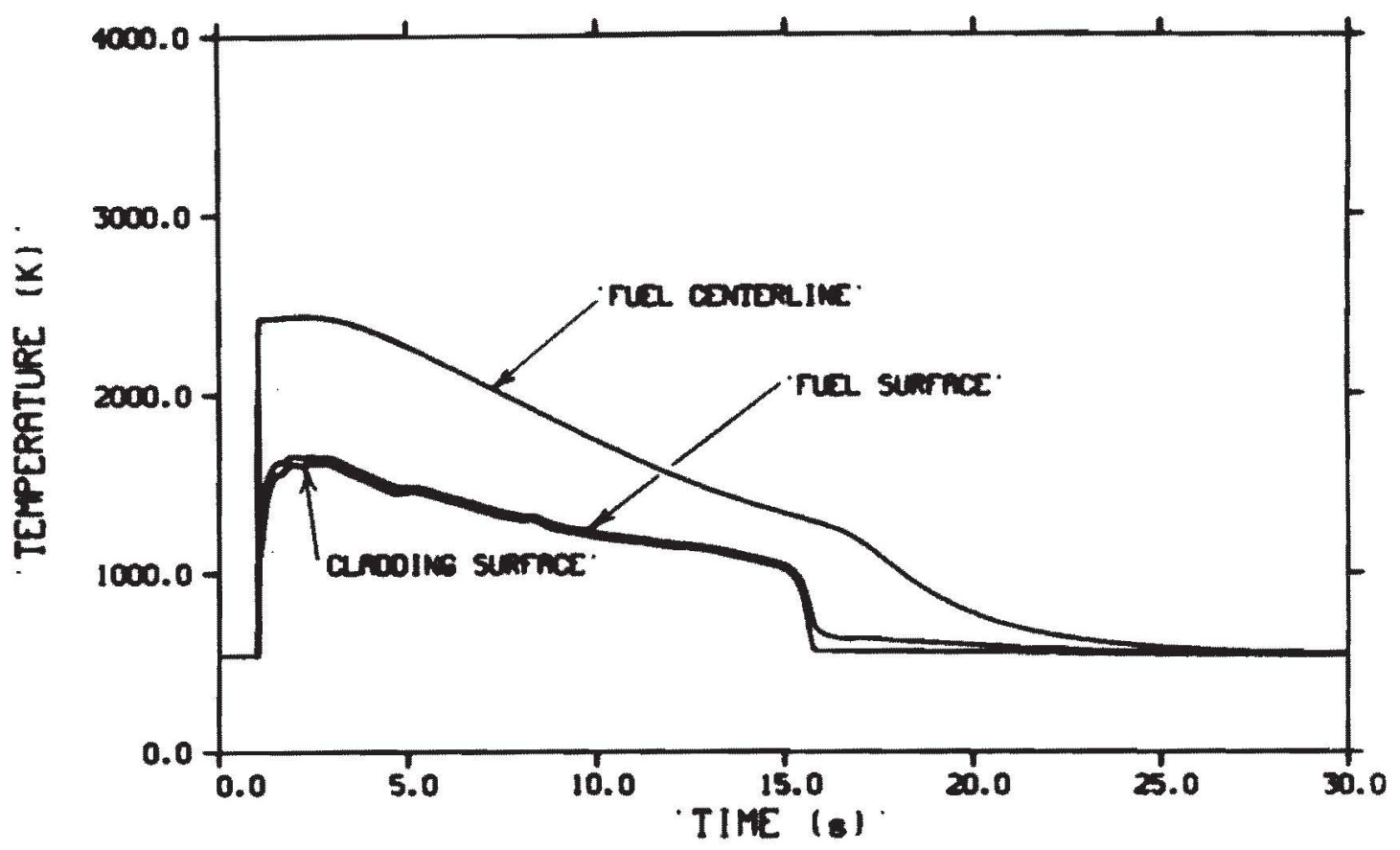

Fig. 6 Fuel rod temperature histories at the axial power peak location for an $315 \mathrm{~J} / \mathrm{a}$ pellet surface deposition.

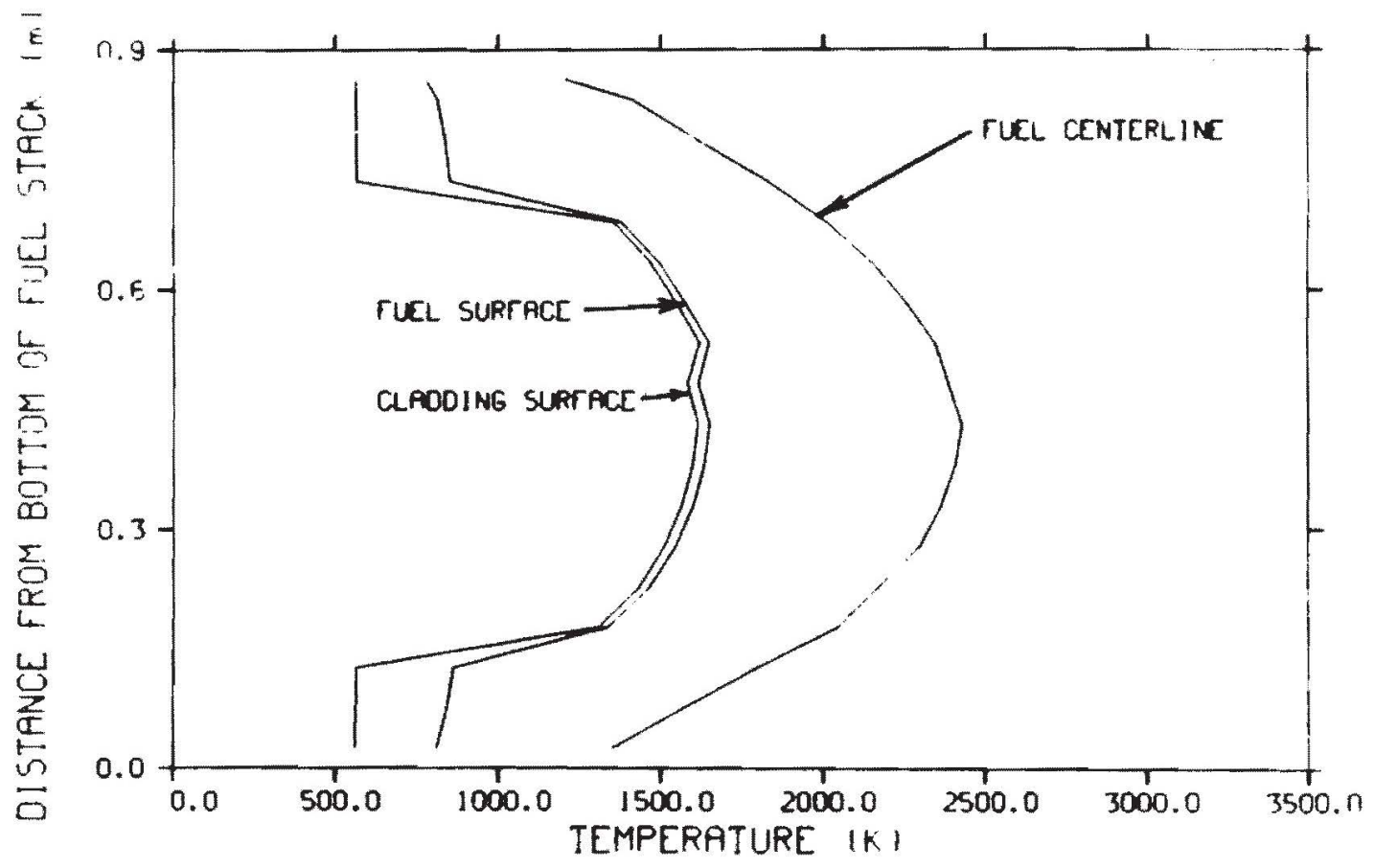

Fig. 7 Axial fuel centerline, fuel surface, and claddin surface temperature proflles at the time of the maximum cladding surface temperature for an $815 \mathrm{~J} / \mathrm{g}$ pellet surface, 


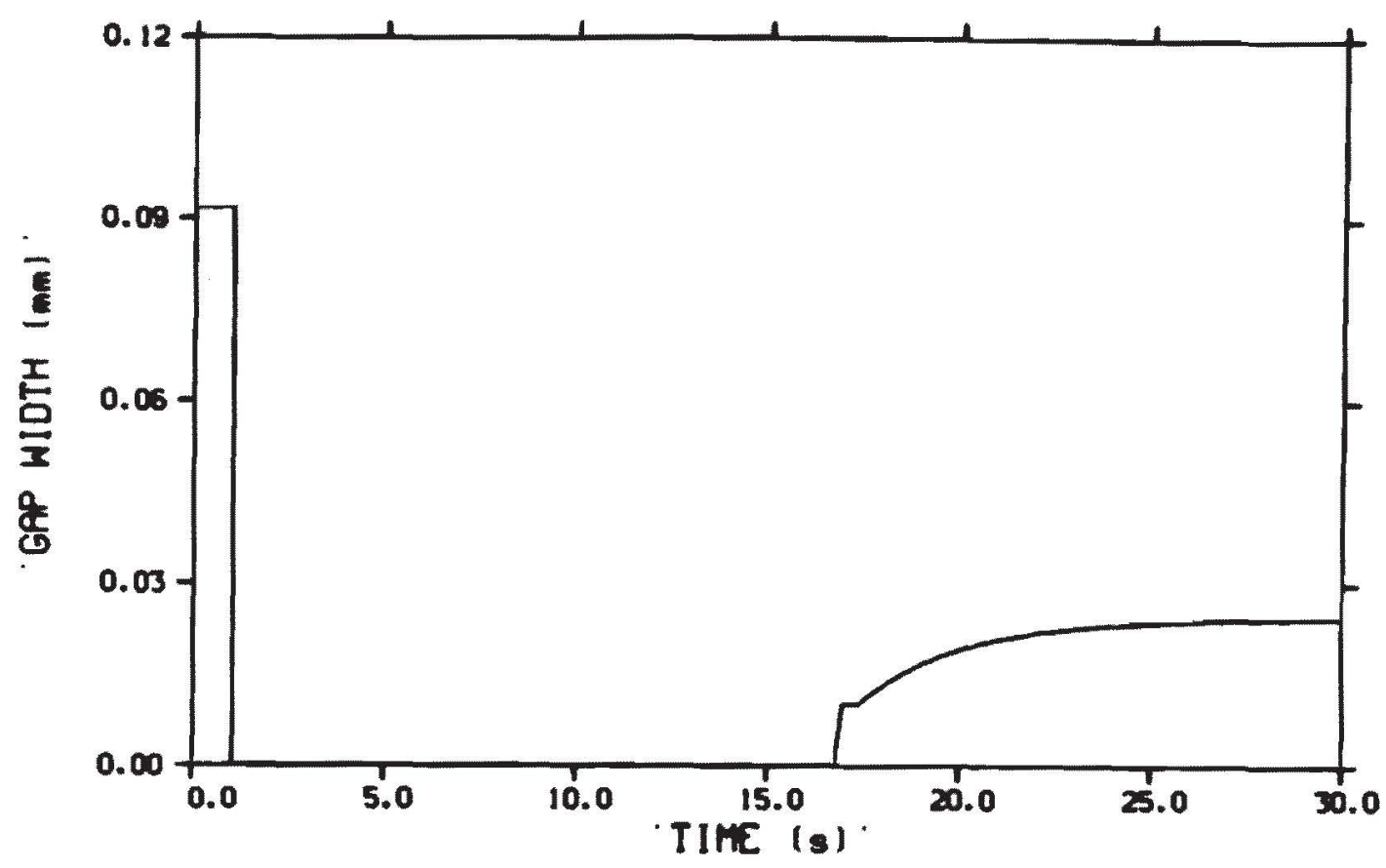

Fig. 8 Fuel rod gap width history at the axial power peak location for an $815 \mathrm{~J} / \mathrm{a}$ pellet surface energy deposition.

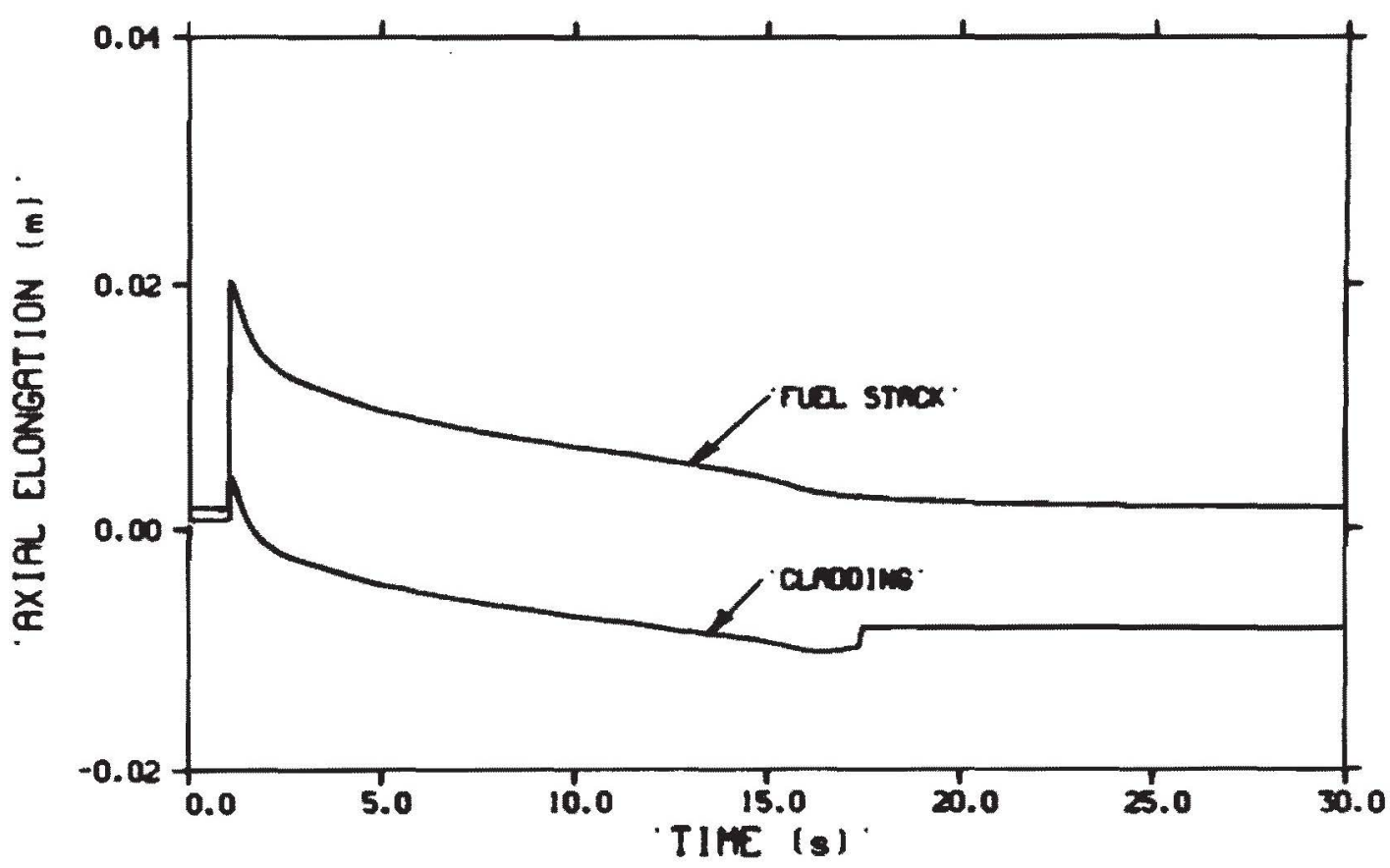

Fig. 9 Fuel stack and cladding axial elongation histories for an $815 \mathrm{~J} / \mathrm{g}$ pellet surface energy deposition. 
Figure 6 illustrates the fuel centerline, fuel surface, and cladding surface temperature histories at the axial power peak elevation of the fuel rod. Almost immediately following the transient, the three temperatures reach their maximums. The maximum fuel centerline temperature is $2440 \mathrm{~K}$. The maximum pellet surface and cladding surface temperatures are 1655 and $1615 \mathrm{~K}$, respectively. Neither the fuel nor the cladding temperatures indicate melting at their respective radial locations. In fact, for this energy deposition, fuel or cladding melting was not indicated anywhere in the fue 1 rod. All three temperatures of Figure 6 begin ramping down after peaking. At about $14.5 \mathrm{~s}$ after transient initiation the pellet and cladding surface temperatures drop sharply, indicating quenching (collapse of film boiling) at the axial power peak elevation. The fuel rod is completely quenched, according to FRAP-T4 at about $15.2 \mathrm{~s}$ after transient initiation.

Figure 7 illustrates the FRAP-T4 calculated axial fuel centerline, fuel surface, and cladding surface temperature profiles for the $815 \mathrm{~J} / \mathrm{g}$ energy deposition. The profiles represent a time of $1.86 \mathrm{~s}$ after initiation of the transient when the cladding surface temperature is at a maximum. The cladding and pellet surface profiles indicate which axial nodes are in film boiling at this time (the higher temperatures). FRAP-T4 predicted that $72 \%$ of the fue 1 stack length will enter film boiling immediately after transient initiation.

Gap width at the axial power peak elevation, illustrated in Figure 8, drops immediately to zero from a pre-transient width of $0.092 \mathrm{~mm}$ and remains closed for about $16 \mathrm{~s}$. The gap then reopens, increasing first to $0.010 \mathrm{~mm}$. This gap reopening corresponds to the collapse of film boiling at the axial power peak location (Figure 6 ). After the initial jump, the gap continues to widen, asymptotically approaching $0.025 \mathrm{~mm}$.

Figure 9 illustrates the axial elongation of the fuel stack and cladding as calculated by FRAP-T4. Both curves peak shortly after initiation of the transient. The magnitudes of the peaks are $20.2 \mathrm{~mm}$ for the fuel stack and $4.2 \mathrm{~mm}$ for the cladding, corresponding to changes 
of 18.5 and $3.4 \mathrm{~mm}$ from the pre-transient lengths. Shortly before reaching the maximum fuel stack and cladding elongations and continuously thereafter to about $17 \mathrm{~s}$, the fuel-cladding gap is closed, and as a result, FRAP-T4 assumes that cladding expansion (contraction) parallels fuel stack expansion (contraction). This assumption results in the negative cladding elongation, or contraction, seen in Figure 9. At about $17 \mathrm{~s}$, when the gap opens, the cladding springs back a little leaving $8.3 \mathrm{~mm}$ permanent shrinkage of the cladding length. The idealization by FRAP-T4 of no slippage between fuel and cladding is believed to be incorrect in this case. Instead of the large contraction of the cladding's axial length indicated, fuel pellet separation is expected.

\subsubsection{FRAP-T4 Calculations for a Pellet Surface Energy Deposition} of $1020 \mathrm{~J} / \mathrm{g}$. The results of the FRAP-T4 analysis for a pellet surface energy deposition of $1020 \mathrm{~J} / \mathrm{g}$ are illustrated by Figures 10 through 13. For this case, the power transient was initiated at $1.0 \mathrm{~s}$, and the analysis was continued for $29 \mathrm{~s}$.

Figure 10 depicts the fuel centerline, fuel surface, and cladding surface temperature histories for the axial power peak elevation. As for the $815 \mathrm{~J} / \mathrm{g}$ deposition calculations, the temperatures are shown to peak shortly after transient initiation. The magnitudes of the respective peaks are 2870,2080 , and $2040 \mathrm{~K}$. Neither the fuel nor the cladding temperatures indicate melting at the fuel centerline or cladding surface. There was no fuel or cladding melting indicated anywhere in the rod for this energy deposition, however, the cladding surface temperature of $2040 \mathrm{~K}$ is very close to melting and indicates that the cladding strength will be seriously impaired. Rod quenching at the axial power peak elevation is indicated by the sharp drop of the fuel and cladding surface temperatures at about $18.5 \mathrm{~s}$ following the transient. The entire rod length was quenched at about $19.5 \mathrm{~s}$ after transient initiation.

Figure 11 illustrates the FRAP-T4 calculated axial fuel centerline, fuel surface, and cladding surface temperature profiles for the $1020 \mathrm{~J} / \mathrm{g}$ energy deposition. The profiles represent a time of $1.75 \mathrm{~s}$ after the 


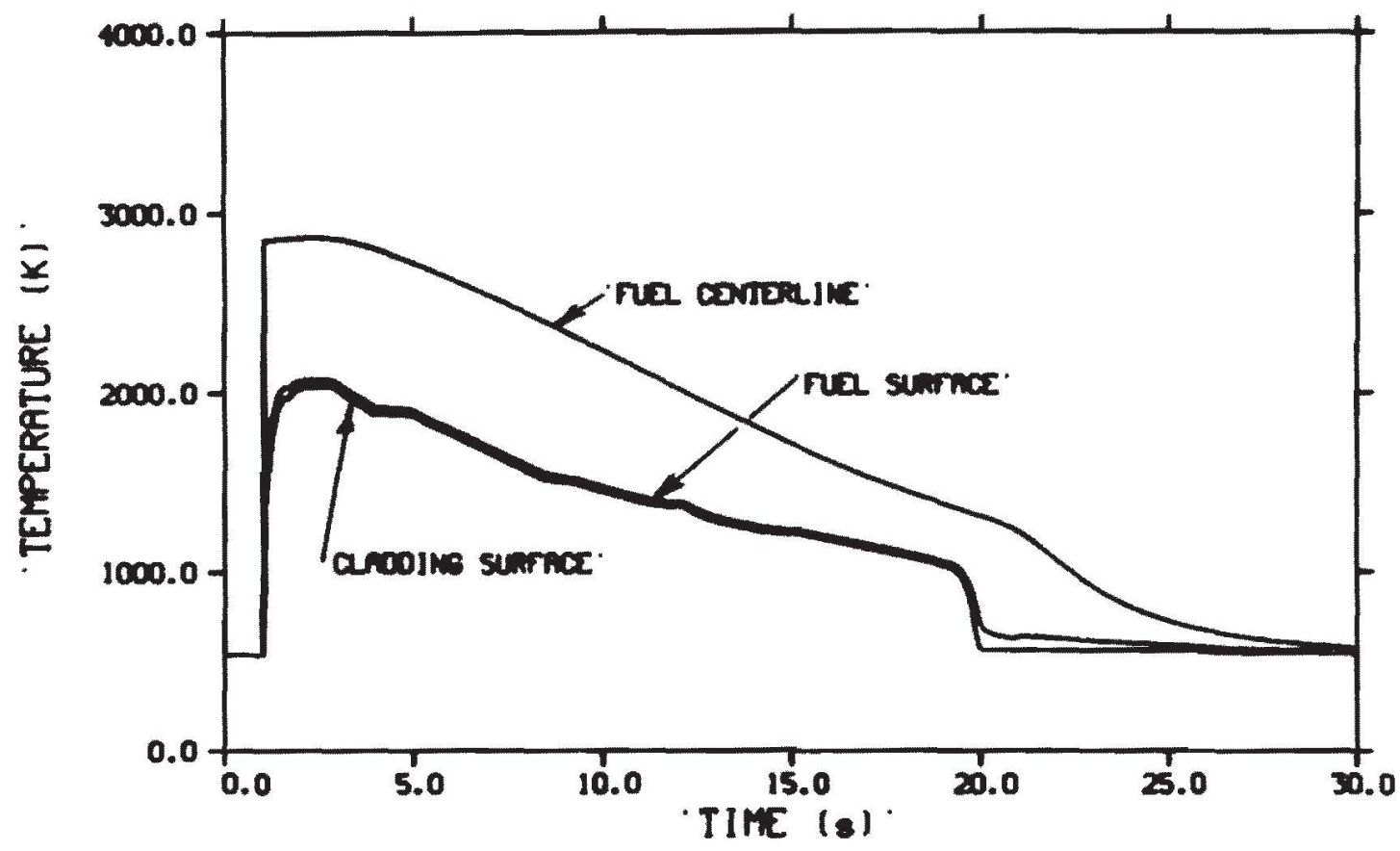

Fig. 10 Fuel rod temperature histories at the axial power peak location for a $1027 \mathrm{~J} / \mathrm{g}$ pellet surface deposition.

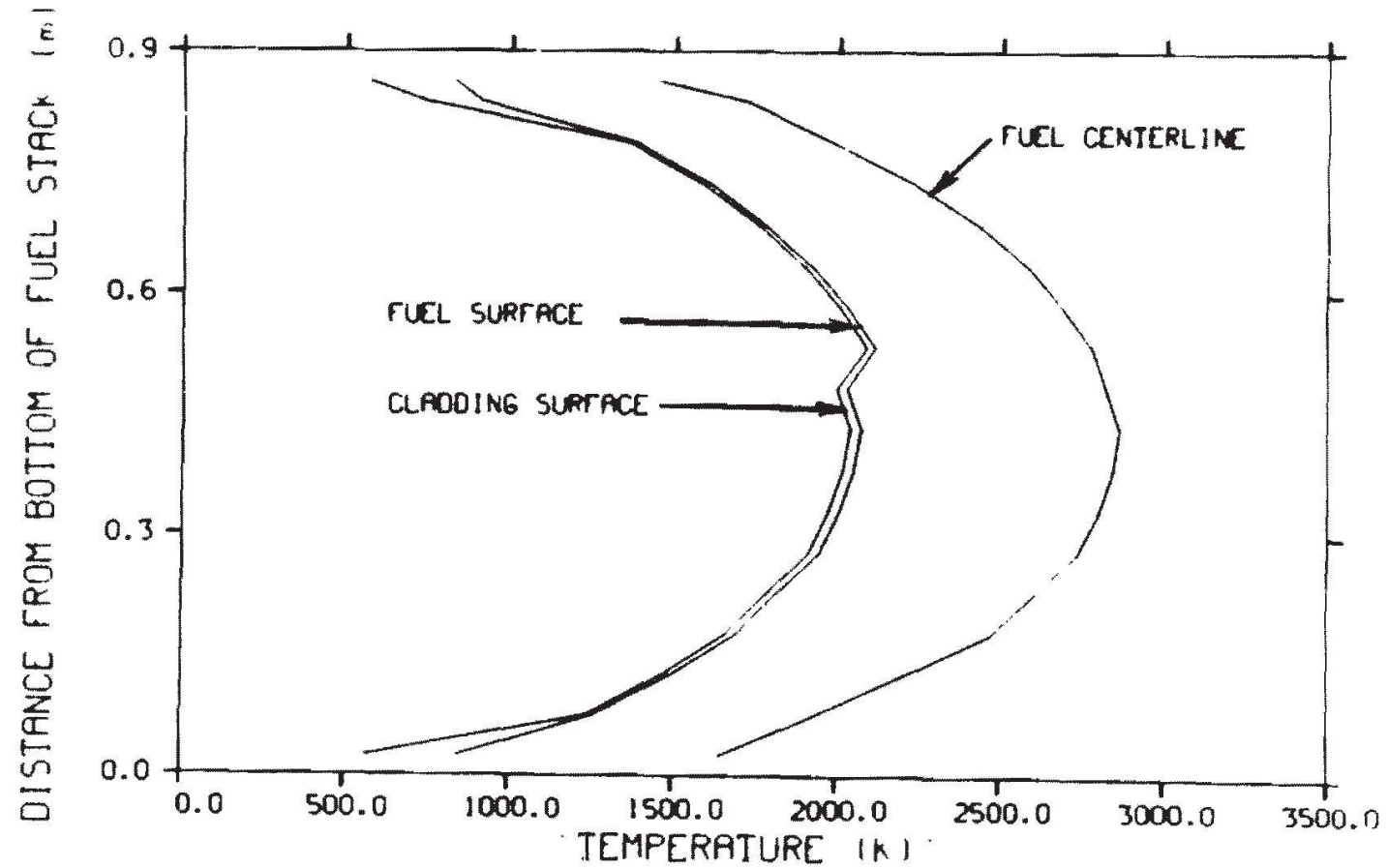

Fig. 11 Axial fuel centerline, fuel surface, and claddinn surface temperature profiles at the time of the maximum cladding surface temperature for a $1020 \mathrm{~J} / \mathrm{g}$ pellet surface energy deposition. 


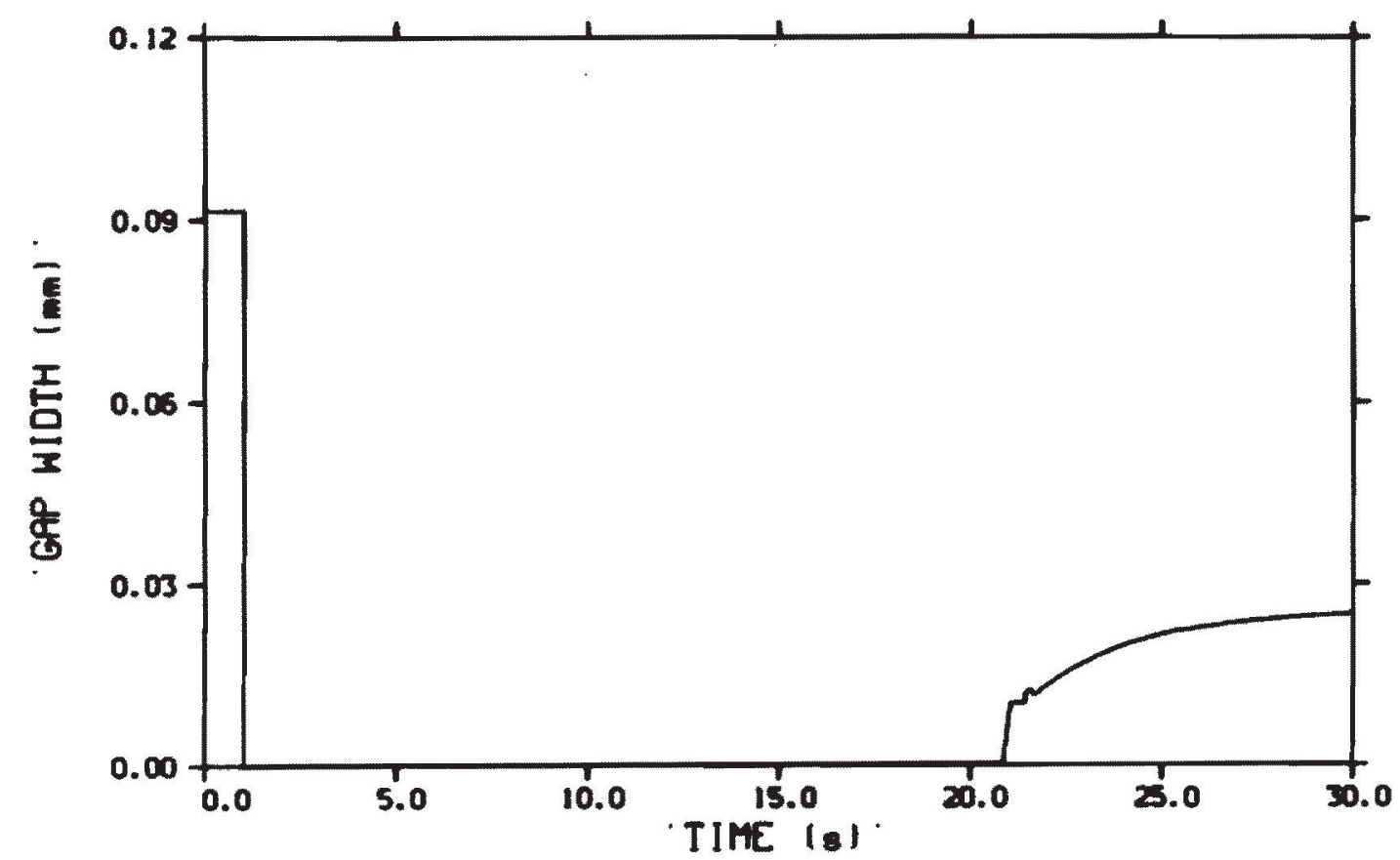

Fic. 12 Fuel rod gap width history at the axial power peak location for a $1020 \mathrm{~J} / \mathrm{g}$ pellet surface energy deposition.

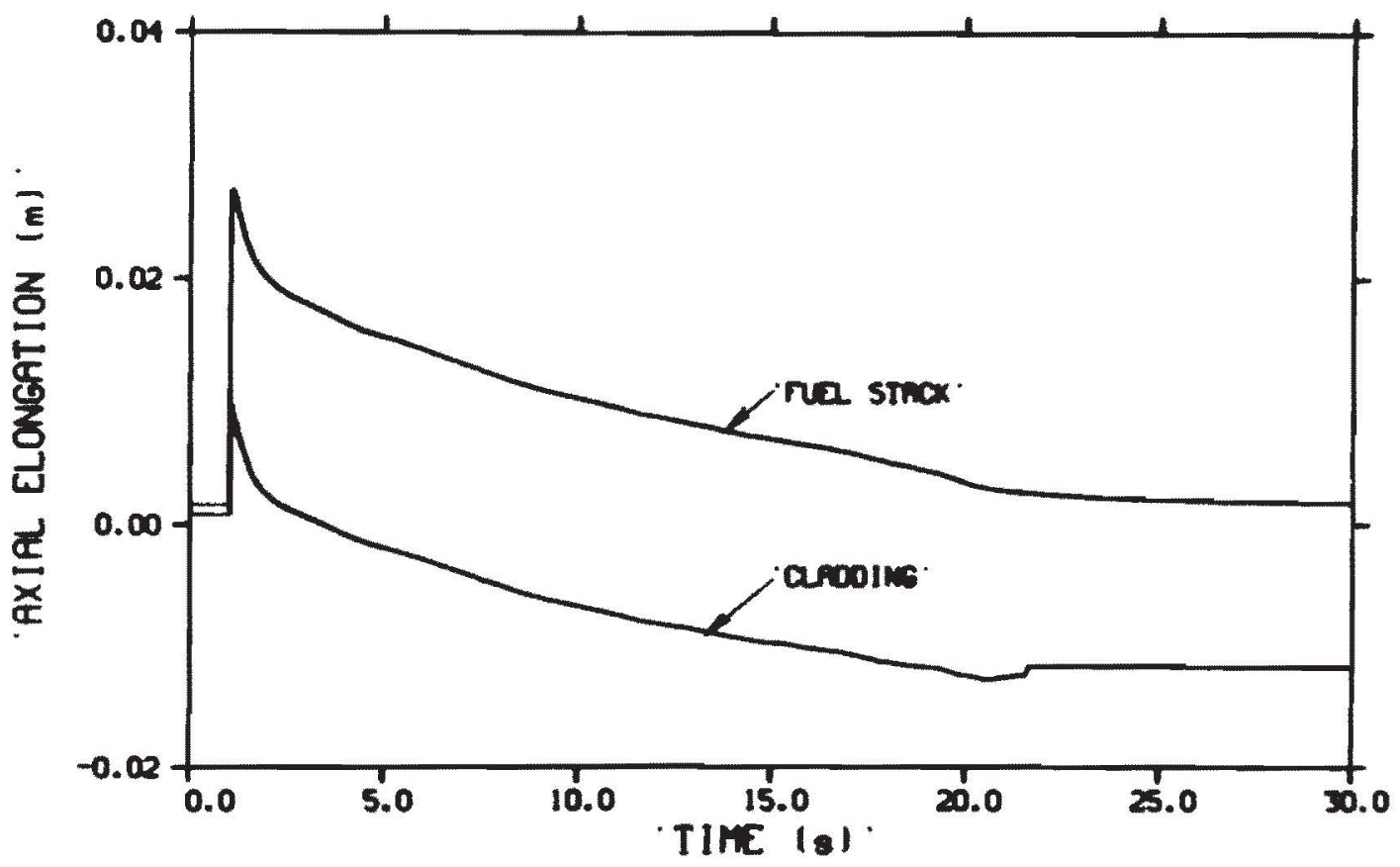

Fin, 13 Fuel stack and cladding axial elongation histories for a $1020 \mathrm{~J} / \mathrm{g}$ pellet surface energy deposition. 
start of the power transient when the cladding surface temperature is maximum. They demonstrate that essentially the whole length of the fuel stack was in the film boiling mode at this time. The FRAP-T4 calculations further indicated that film boiling spread over the fuel stack length immediately following the power transient.

Figure 12 shows that the fuel-cladding gap for the fuel rod closes shortly after initiation of the power transient. The pre-transient gap was $0.092 \mathrm{~mm}$. The gap remains closed for almost $20 \mathrm{~s}$ at which time it reopens, increasing first to $0.010 \mathrm{~mm}$. This reopening is a result of rod quenching. The fuel-cladding gap then continues to open asymptotically to $0.025 \mathrm{~mm}$.

Fuel stack and cladding axial elongation is illustrated by Figure 13. Again, as in the lower energy deposition analysis, the clatding elongation is forced to follow that of the fuel stack while the fuel-cladding gap is closed. Shortly after $20 \mathrm{~s}$, when the gap reopens, the cladding "spring back" is indicated. The magnitudes of the elongation peaks are 27.2 and $9.6 \mathrm{~mm}$, corresponding to changes of 25.5 and $8.8 \mathrm{~mm}$ in the pre-transient lengths. The final cladding length is predicted hy FRAP-T4 to be $11.8 \mathrm{~mm}$ shorter than its initial cold length. Again, instead of this axial cladding shrinkage, fuel pellet separation is expected to occur.

\subsubsection{FRAP-T4 Calculations for a Pellet Surface Energy Deposition} of $1225 \mathrm{~J} / \mathrm{g}$. The results of the FRAP-T4 analysis for a $1225 \mathrm{~J} / \mathrm{g}$ energy deposition are illustrated by Figures 14 through 17 . In this case, the power transient was initiated at $1.0 \mathrm{~s}$ and run for $26 \mathrm{~s}$.

Figure 14 depicts the axial fuel centerline, fuel surface, and cladding surface temperature histories at the axial power peak elevation of the fue 1 rod. The respective temperatures reach maximum values aimost immediately after the start of the power transient. The indicated peak fuel centerline temperature is the $\mathrm{UO}_{2}$ melting point of $3113 \mathrm{~K}$. The peak fuel surface temperature is $2175 \mathrm{~K}$, and the peak cladding surface 


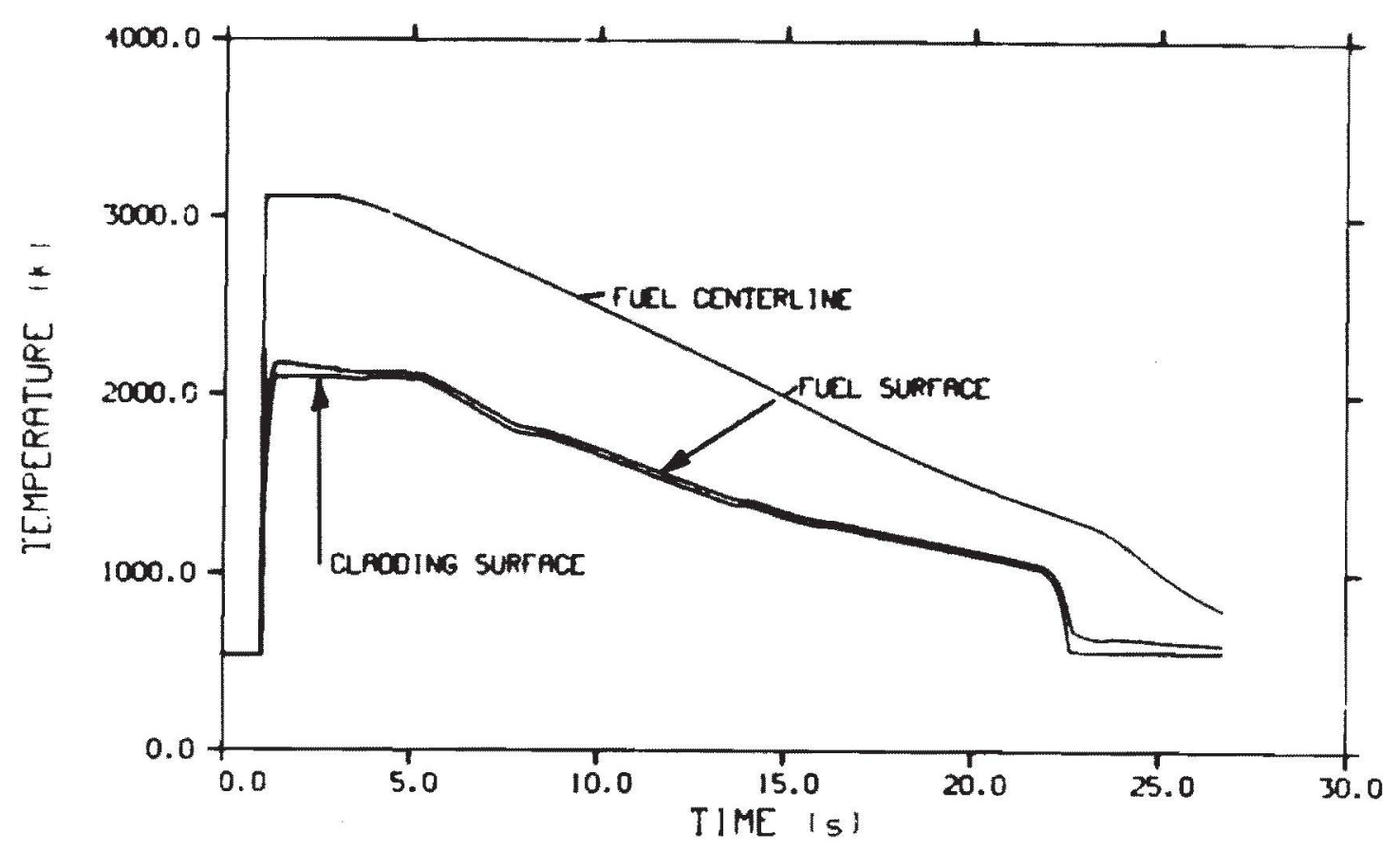

Fig. 14 Fuel rod temperature histories at the axial power peak location for a $1225 \mathrm{~J} / \mathrm{q}$ pellet surface energy deposition.

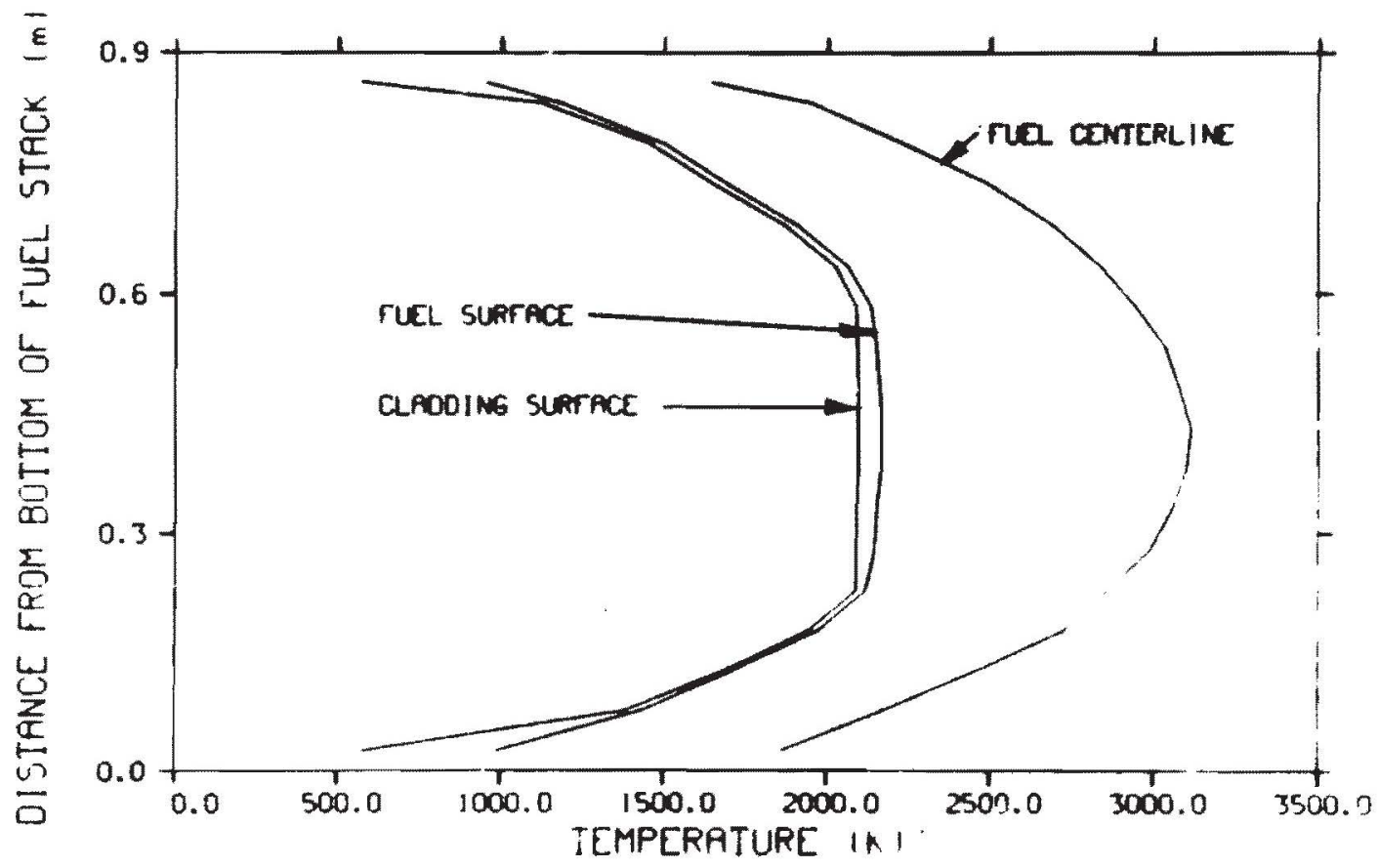

Fig, 15 Axial fuel centerline fuel surface, and cladding surface temperature profiles at the time of the maximum cladding surface temperature for a $1225 \mathrm{~J} / \mathrm{g}$ pellet surface energy deposition. 


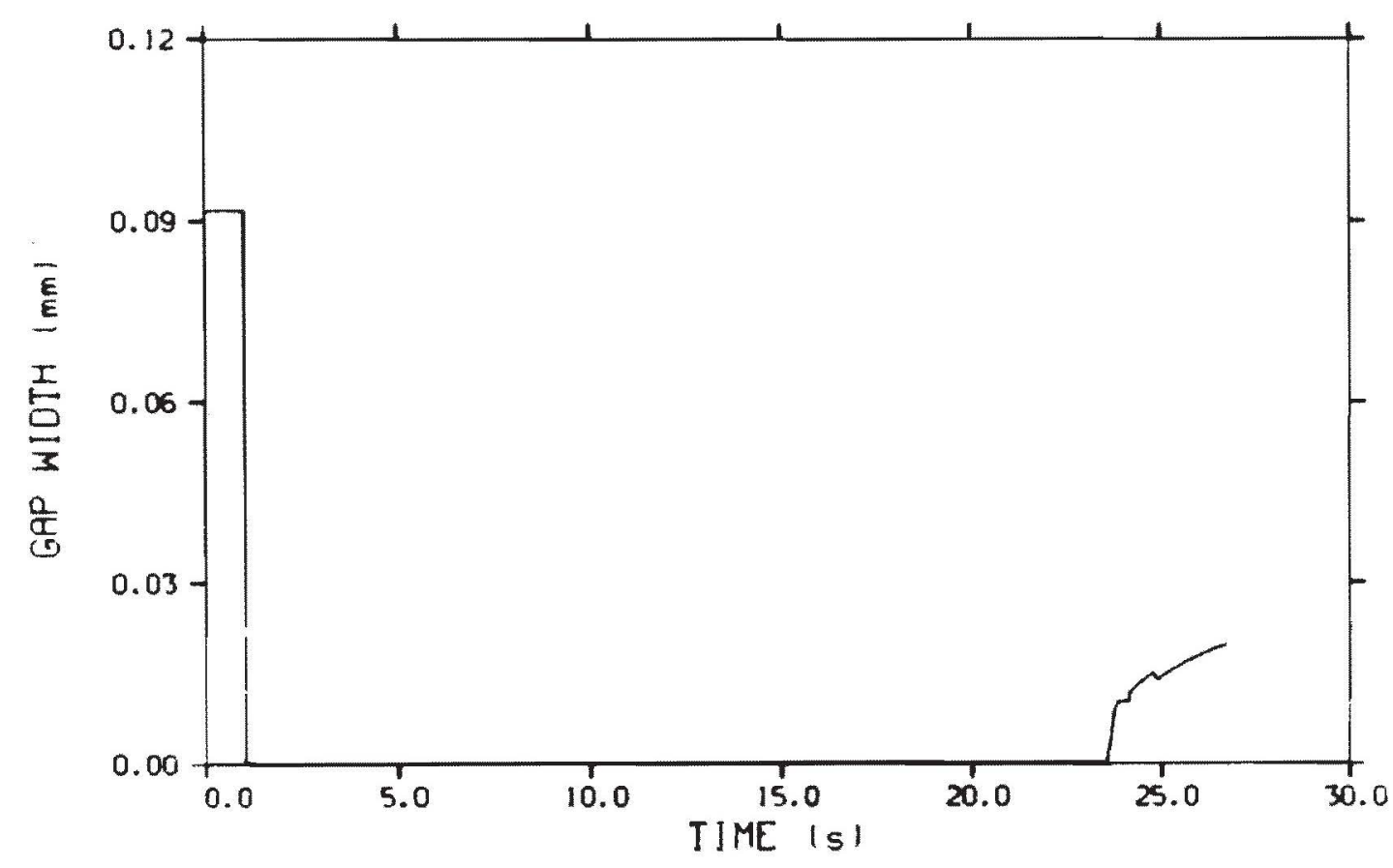

Fiç. 16 Fuel rod gap width history at the axial power peak location for a $1225 \mathrm{~J} / \mathrm{g}$ pellet surface deposition.

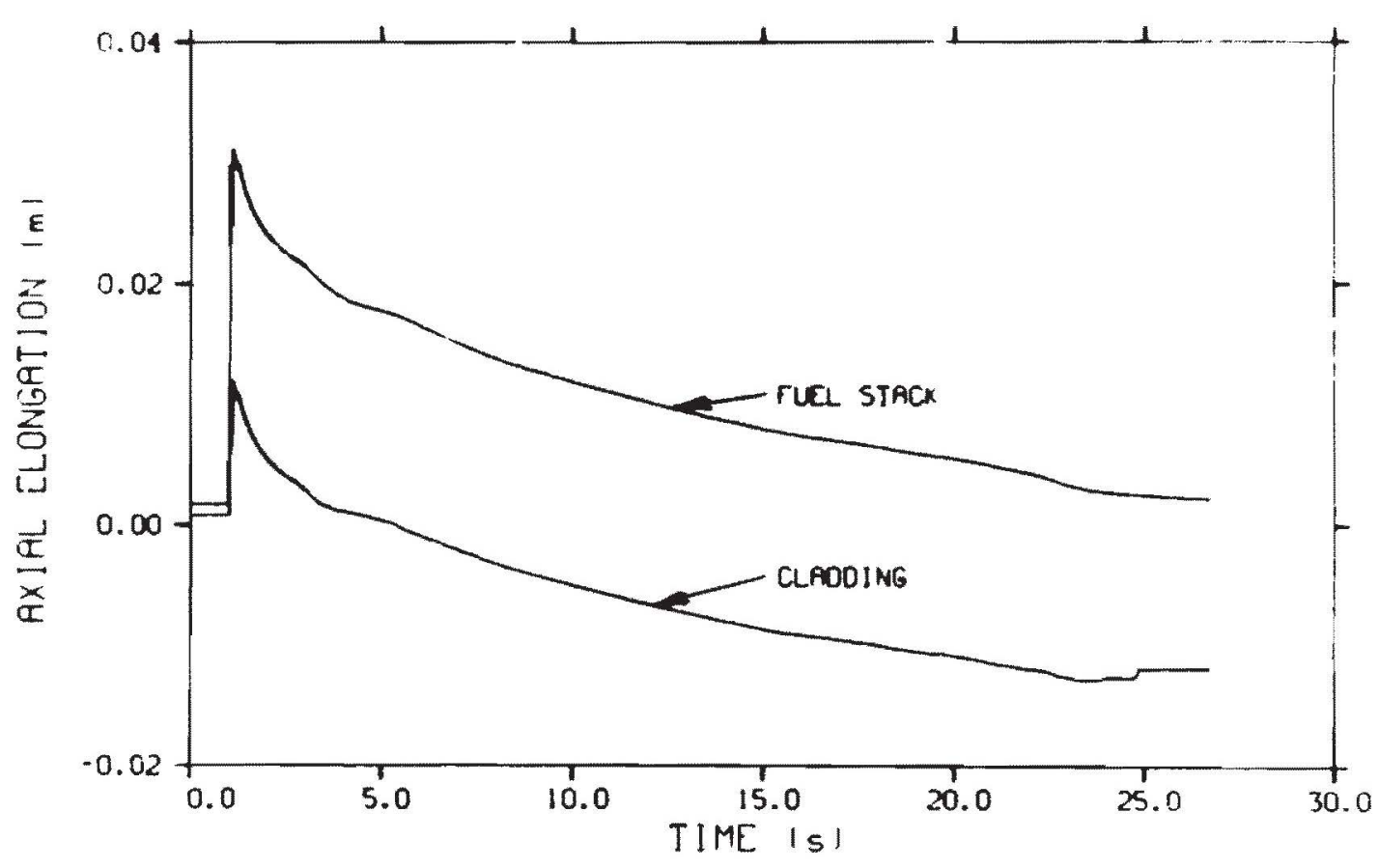

Fio. 17 Fuel stack and cladding axial elongation historles for a $1225 \mathrm{~J} / \mathrm{g}$ pellet surface energy deposition. 
temperature is $2098 \mathrm{~K}$, the melting temperature for zircaloy. FRAP-T4 indicated that incipient fuel melting occurs first at $0.05 \mathrm{~s}$ into the transient at a fuel pellet radius of $3.5 \mathrm{~mm}$ and an elevation above the bottom of the fuel stack of $0.43 \mathrm{~m}$. The percentage of molten fuel reaches a maximum value of $5.6 \%$ at $0.07 \mathrm{~s}$ into the transient with a maximum fuel melt radius calculated to be $3.5 \mathrm{~mm}$ or $85 \%$ of the initial fuel pellet radius. The fuel at the centerline resolidifies after $1.73 \mathrm{~s}$. Incipient cladding surface melting occurs at $0.65 \mathrm{~s}$ after transient initiation. Approximately $35 \%$ of the rod experiences cladding surface melting with the entire surface resolidifying again in less than $1.35 \mathrm{~s}$. At approximately $21.5 \mathrm{~s}$ the pellet and cladding surface temperatures, as illustrated by Figure 14, drop sharply indicating quenching of the rod at the axial power peak elevation. The fuel rod is completely quenched at about $22.5 \mathrm{~s}$ after the transient initiation.

Figure 15 illustrates the axial fuel centerline, fuel surface, and cladding surface temperature profiles for the $1225 \mathrm{~J} / \mathrm{g}$ pellet surface energy deposition. The profiles represent a time of $1.65 \mathrm{~s}$ after initiation of the transient when cladding surface temperature is at the maximum. The temperature curves indicate that the film boiling region extends over nearly the entire rod length at this time. The FRAP-T4 calculations further indicate that film boiling spreads over the entire rod length almost immediately following the start of the power transient.

The fuel-cladding gap, as illustrated by Figure 16, closes almost immediately. The pre-transient gap was $0.092 \mathrm{~mm}$. It opens approximately $22.5 \mathrm{~s}$ later, jumping first to $0.010 \mathrm{~mm}$ at the time of rod quench. After the initial increase, the gap width continues to increase asymptotically, reaching $0.020 \mathrm{~mm}$ by the time the calculations are halted. If the calculations had continued, it is believed that the final value of the gap width would have been approximately $0.025 \mathrm{~mm}$, as it was for the lower energy depositions.

Figure 17 illustrates the axial elongation of the fuel stack and cladding as calculated by FRAP-T4. The two curves are similar to those 
for the lower energy depositions. The peak magnitudes are $29.7 \mathrm{~mm}$ for the fuel stack and $11.4 \mathrm{~mm}$ for the cladding, corresponding to changes of 28.0 and $10.6 \mathrm{~mm}$ in the pre-transient lengths. The curves remain parallel until the fuel-cladding gap reopens at approximately $24.5 \mathrm{~s}$ after transient initiation. After the gap opens the cladding retains $11.9 \mathrm{~mm}$ of permanent shrinkage. Again, this shrinkage is not anticipated to actually occur. Instead, fuel pellet separation is expected.

3.3.4 Fuel Radial Temperature Profile. The fuel rod radial power profile presented in Section 3.1 indicates that during the power transients the maximum energy deposition will be at the fuel pellet outer surface. Because of this, the peak fuel temperatures calculated by FRAP-T4 do not occur at the fuel centerline. Instead, the combination of maximum energy deposition occurring at the pellet surface and the normal heat flux out of the pellet surface combine to locate the peak fuel temperatures at outer radial locations which vary with time.

Figure 18 presents the radial temperature profiles for the 815, 1020, and $1225 \mathrm{~J} / \mathrm{g}$ energy depositions. The time represented by each profile corresponds to that which yields the maximum peak-to-centerline temperature ratio.

As illustrated in Figure 18, the peak fuel temperatures are shown to be located at approximately $84 \%$ of the pellet radius for the $815 \mathrm{~J} / \mathrm{g}$ energy deposition, $87 \%$ of the pellet radius for the $1020 \mathrm{~J} / \mathrm{g}$ deposition, and $89 \%$ of the pellet radius for the $1225 \mathrm{~J} / \mathrm{g}$ deposition. The peak-tocenterline temperature ratios for the three cases are, respectively, $1.07,1.06$, and 1.05 .

\subsubsection{Cladding Temperature versus Peak Energy Deposition.} Figure 19 is a plot of the maximum cladding temperatures versus peak pellet surface energy depositions for the three $9.70 \mathrm{~mm}$ OD fuel rod behavior analyses discussed in Sections 3.3.1,3.3.2, and 3.3.3, and 


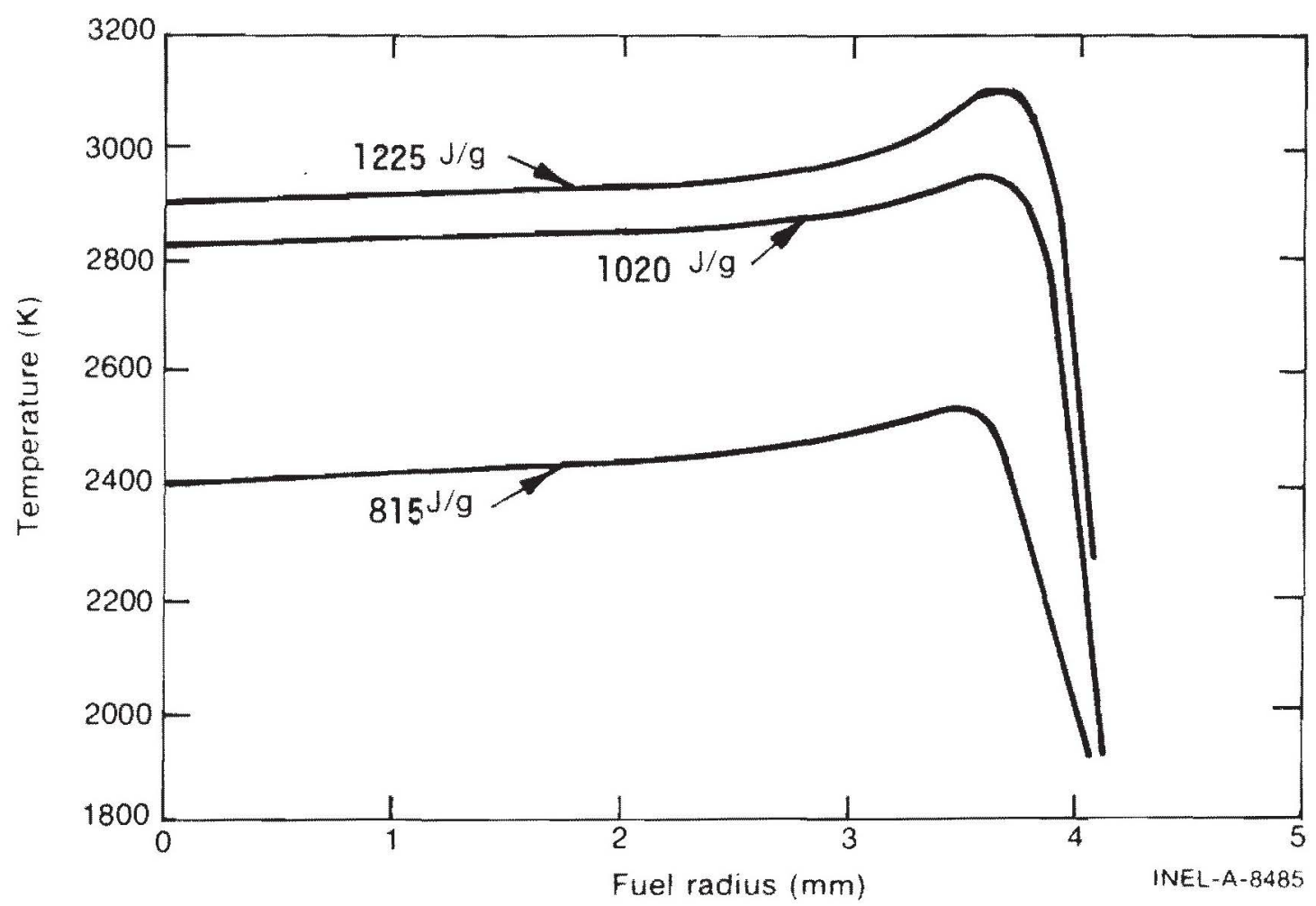

Fig. 18 Radial temperature profiles of fuel at time correspondina to peak centerline temnerature for nellet surface energy depositions of 815,1020 , and $1225 \mathrm{~J} / \mathrm{a}$.

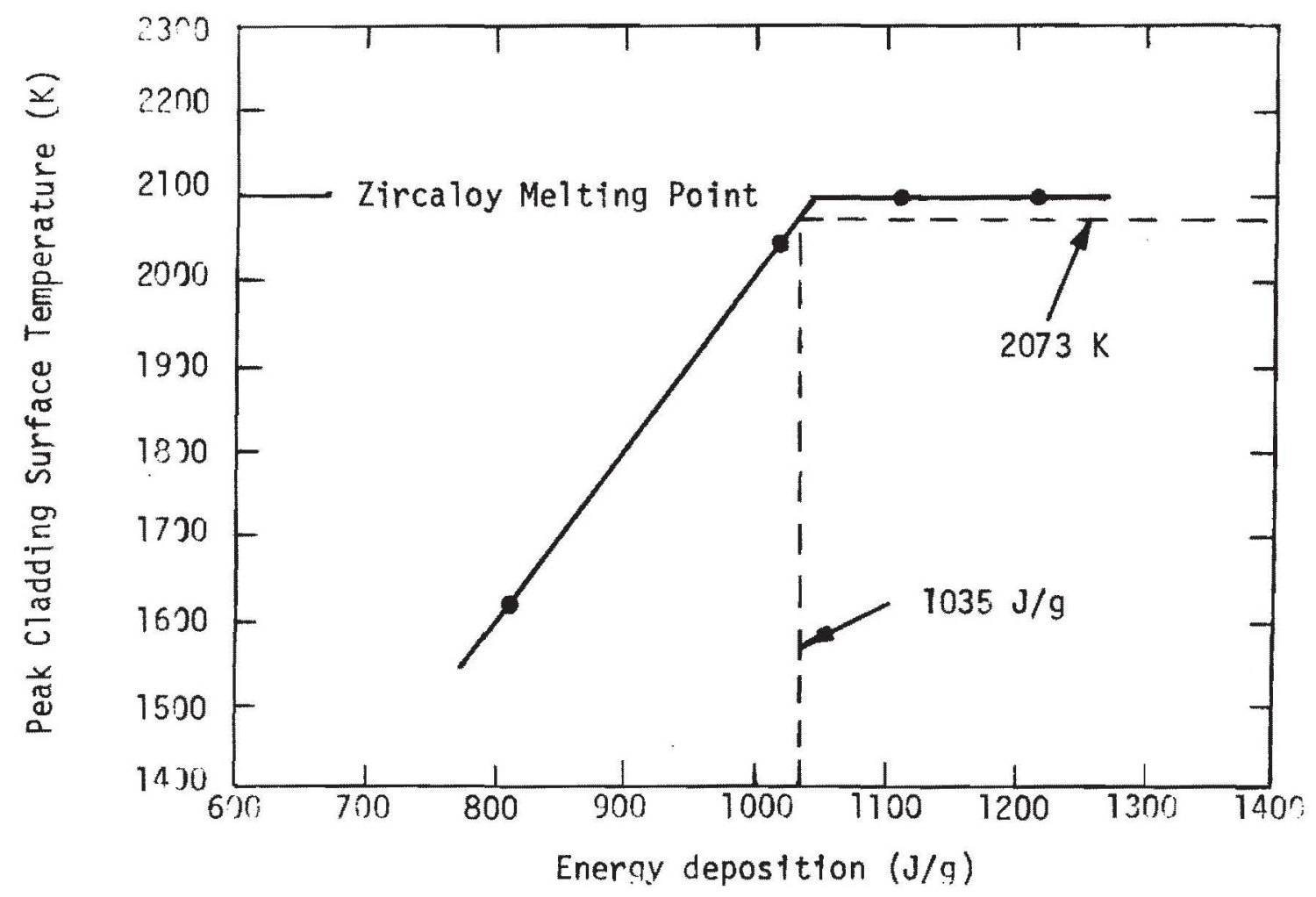

Fin. 19 Peak cladding temperature as a function of pellet surface energy deposition. 
an additional analysis that was not presented $[a]$. The curve illustrates the effect of pellet surface energy deposition on maximum cladding temperature and, therefore, the likely energy deposition fallure threshold. This indicates that, based on FRAP-T4 calculations, a pellet surface energy deposition of $1045 \mathrm{~J} / \mathrm{g}(250 \mathrm{cal} / \mathrm{g})$ at the axial power peak elevation results in incipient cladding surface melting at the power peak elevation for the $9.70 \mathrm{~mm}$ on fue 1 rods. A pellet surface energy deposition of $1035 \mathrm{~J} / \mathrm{g}(247 \mathrm{cal} / \mathrm{g})$ corresponds to a peak cladding temperature of $2073 \mathrm{~K}$. It is believed that at $2073 \mathrm{~K}$, the cladding will be weak enough to fail due to low pressure cladding rupture. This limit was chosen based on the results of the previous RIA tests which will be discussed in Section 4.

\subsubsection{FRAP-T4 Calculations for a Radially Averaged Energy Depo-} sition of $2510 \mathrm{~J} / \mathrm{g}$. This case was run to provide baseline data for predicting the mode of failure for the final high energy phases of the Scoping Test (RIA-ST-4 and RIA-ST-5). These two phases of the Scoping Test are non-programmatic and intended to address PBF safety concerns.

The $10.73 \mathrm{~mm}$ OD fuel rod, according to FRAP-T4 will undergo extensive disintegration by melting as a result of the $2510 \mathrm{~J} / \mathrm{g}$ radially averaged energy deposition. Incipient rod failure was indicated at $0.035 \mathrm{~s}$ as the result of cladding overstress induced by pellet-tocladding interaction. At $0.075 \mathrm{~s}, 60 \%$ of the total fuel volume had passed the melting point with $55 \%$ of the axial length of the fuel stack beyond it. A maximum fuel temperature of $4950 \mathrm{~K}$ was reached. Incipient cladding surface melting was indicated at $0.08 \mathrm{~s}$, and $64 \%$ of the axial surface length was molten at $0.236 \mathrm{~s}$. FRAP-T4 does not have a $\mathrm{UO}_{2}$ vapor pressure model at present, thereby precluding the calculations from indicating this expected failure mechanism.

[a] A similar FRAP-T4 analysis was made at $1120 \mathrm{~J} / \mathrm{g}$ but was run on ly long enough to determine peak cladding surface temperature. The results indicated cladding melting. 


\subsection{Cladding Embrittlement Analysis}

Past test experience with high temperature cladding oxidation has provided two criteria for evaluating the likelihood of rod failure, due to cladding embrittlement, based on reaction layer thicknesses. To use these criteria, the FRAP-T4 predicted cladding surface temperature histories for the 815,1020 , and $1225 \mathrm{~J} / \mathrm{g}$ pellet surface energy depositions were used to run three BUILD5 computer code calculations. The BUILD5 code applies the Cathcart correlation ${ }^{[6]}$ to calculate zircaloy one-side reaction layer thicknesses when given a surface temperature history. Although the FRAP-T4 histories exceed the cladding temperature range of the BUILD5 code, it was used as the only available method of evaluating the cladding embrittlement failure mode. The BUILD5-calculated reaction layers used in the cladding failure criteria are the outer $\mathrm{ZrO}_{2}$ and oxygen-stabilized alpha layers ( $\alpha$ - layer). Fuel-cladding contact following the energy depositions causes the formation of another oxygenstabilized alpha layer on the inside surface of the cladding. The thickness of this inner alpha layer can be approximated by that of the outer layer. This approximation is based on the postirradiation examination of numerous cladding specimens.

Doubling the BUILD5 predicted alpha layer thickness and adding the $\mathrm{ZrO}_{2}$ layer thickness, yields an approximation of the total expected cladding participation in the reaction process. For the 815, 1020, and $1225 \mathrm{~J} / \mathrm{g}$ energy depositions respectively, the total thickness of the reaction layers are;

$$
\begin{aligned}
& \text { (1) } \mathrm{ZrO}_{2}=0.013 \mathrm{~mm} \text { and } \alpha=0.032 \mathrm{~mm} \text {, } \\
& \text { (2) } \mathrm{ZrO}_{2}=0.043 \mathrm{~mm} \text { and } \alpha=0.150 \mathrm{~mm} \text {, and } \\
& \text { (3) } \mathrm{ZrO}_{2}=0.072 \mathrm{~mm} \text { and } \alpha=0.280 \mathrm{~mm} \text {. }
\end{aligned}
$$

The two criteria for rod failure during reactor operation, due to high temperature cladding oxidation, can be expressed by the inequalities:

$$
\begin{aligned}
& \text { (1) } F(w)<0.62 \text {, and } \\
& \text { (2) ECR }>17 \% \text {. }
\end{aligned}
$$


The first criterion indicates that when the fraction of the original cladding thickness that has remained in the beta phase $F(w)$ becomes less than 0.62 , cladding failure due to embrittlement can be expected. " $F(w)$ " can be calculated from the reaction layers using the equation;

$$
F(w)=\left(T h-\alpha-\frac{2 r 0_{2}}{1.54}\right) / T h
$$

where,

$$
\begin{aligned}
\text { Th } & =\text { the original cladding thickness, } \\
\alpha & =\text { the total alpha layer thickness, and } \\
\mathrm{ZrO}_{2} & =\text { the } \mathrm{ZrO}_{2} \text { layer thickness. }
\end{aligned}
$$

The second criterion indicates that when the ECR ratio (equivalent cladding thickness reacted to form $\mathrm{ZrO}_{2}$-to-the oxygen weight fraction in the alpha layers) is greater than $17 \%$, cladding failure due to embrittlement can be expected. "ECR" can be calculated from the reaction layers using this equation;

$$
E C R=\frac{1}{T h}\left[\frac{\mathrm{ZrO}_{2}}{1.54}+\frac{\alpha}{1.54 \sigma}\right] \times 100,
$$

where, $\sigma$ is a factor relating the ratio of oxygen-to-zircaloy in $2 \mathrm{rO}_{2}$ (1.54) to that ratio in oxygen-stabilized alpha-zircaloy; "o" was approximated to be a constant value of 5.3 .

Table IV presents the results of applying these two criteria to the BUILD5-derived reaction layer thicknesses for the 815, 1020, and $1225 \mathrm{~J} / \mathrm{g}$ energy depositions. The table further indicates that, based on the " $F(w)$ " criteria, the $1225 \mathrm{~J} / \mathrm{g}$ pellet surface deposition will provide a cladding surface temperature history that can be expected to result in sufficient cladding embrittlement to induce failure. Figure 20 is a plot of the BUILD5-derived " $F(w)$ " values provided by Table IV, indicating that the minimum pellet surface energy deposition that will result in embrittlement-induced cladding failure is $1110 \mathrm{~J} / \mathrm{g}(265 \mathrm{cal} / \mathrm{g})$. This result, combined with the previous indication (Section 3.3.5) that the failure threshold will be $1035 \mathrm{~J} / \mathrm{g}$ with a maximum cladding temperature 
TABLE IV

REACTION LAYER CLADDING FAILURE CRITERIA RESULTS FOR 815, 1020, AND $1225 \mathrm{~J} / \mathrm{g}$ PELLET SURFACE ENERGY DEPOSITIONS

\section{Energy Deposition

$\frac{(\mathrm{J} / \mathrm{g})}{815}$

1020

1225

$\frac{F(w)[a]}{0.94}$

0.72

0.49

$$
\frac{\operatorname{ECR}^{[\mathrm{b}]}(\%)}{1.9}
$$

7.2

12.7

[a] Rod failure indicated if less than 0.62 .

[b] Rod failure indicated if greater than $17 \%$. 


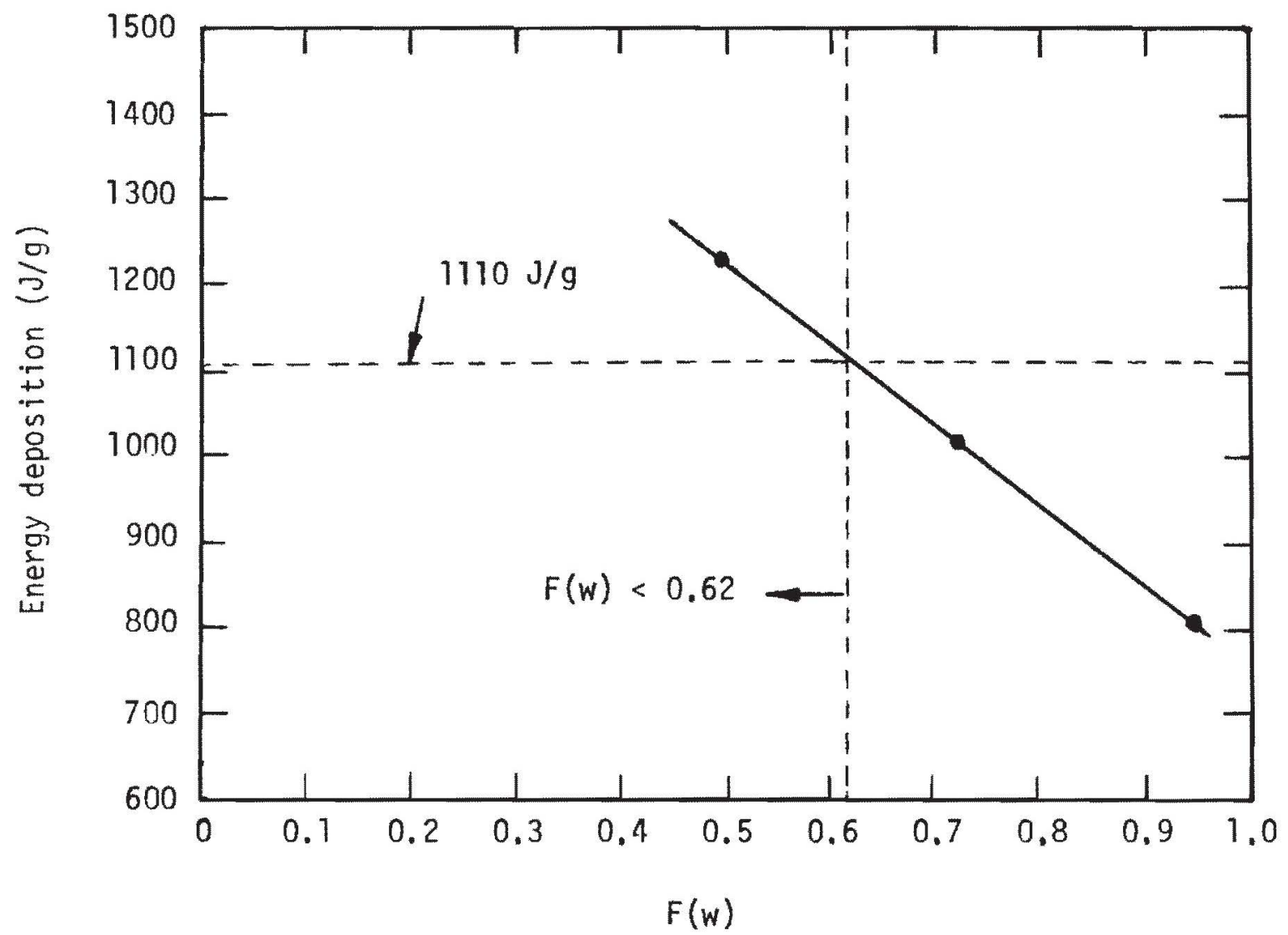

Fig. 20 Fraction of the original cladding thickness that has remained in the beta-zircaloy phase with respect to pellet surface energy deposition. 
should be rupture due to high temperature weakening of the cladding and not brittle fracture.

\subsection{Pressure Pulse Analyses}

The analyses discussed in this section were performed to provide baseline data for predicting the magnitudes of generated pressure pulses for the final high energy phases of the Scoping Test.

Pressure pulses are expected to result from fuel rod failure and possible subsequent fuel-coolant interactions during the 1990 and $2510 \mathrm{~J} / \mathrm{g}$ radially averaged energy depositions of RIA-ST-4 and RIA-ST-5. The magnitudes of these pulses were calculated using the SPIRT computer code. The SPIRT code calculated the generation of super heated steam by molten fuel particles, resulting in rapid pressurization. The method modeled coolant compression within the IPT without including the acoustic filters or thermal swell accumulators.

A single fuel rod with an active length of $0.914 \mathrm{~m}$, a cladding $0 \mathrm{D}$ of $10.73 \mathrm{~mm}$, and a flow shroud ID of $16.3 \mathrm{~mm}$ was considered in both the 2500 and $1990 \mathrm{~J} / \mathrm{g}$ cases. The initial coolant conditions were $538 \mathrm{~K}$, $6.45 \mathrm{MPa}$, and $490 \mathrm{~kg} / \mathrm{s}-\mathrm{m}^{2}\left(85 \mathrm{~cm}^{3} / \mathrm{s}\right)$. Fuel fragmentation weight distribution and particle sizes for the SPIRT computer code calculation were obtained from the results of the SPERT CDC tests. A fuel dispersal time of $1 \mathrm{~ms}$ was used.

The SPIRT calculation for the $2510 \mathrm{~J} / \mathrm{g}$ deposition rod failure case yielded a source pressure of $24.8 \mathrm{MPa}$ with pressure doubling occurring at the top and bottom of the IPT. The pressure wave propagation back and forth through the IPT gave a maximum pressure of $34.5 \mathrm{MPa}$ with a rise time of $7 \mathrm{~ms}$. The $1990 \mathrm{~J} / \mathrm{g}$ deposition rod failure resulted in a calculated pressure pulse of $24.1 \mathrm{MPa}$ with the SPIRT code. SPIRT predicted a pressure doubling of $31.7 \mathrm{MPa}$ at $7 \mathrm{~ms}$ after fuel dispersal. 


\section{RESULTS OF PREVIOUS RIA TESTS}

The applicable experimental data on fuel rod behavior, simulating an RIA, have been obtained from programs carried out in the SPERT Capsule Driver Core $(C D C)$ and TREAT facilities[a]. An ongoing test program at the NSRR $[\mathrm{b}]$ is providing additional applicable data. In each of these facilities, encapsulated oxide fuel with metal cladding was subjected to power transients comparable to those of hypothetical RIAs in light water reactors. The test capsule generally contained stagnant water at atmospheric pressure and room temperature.

Results from these tests have shown that the most important aspect of an RIA or an RIA test, is the magnitude of energy deposited into the fue ${ }^{[7]}$. In RIA experiments of the type carried out in SPERT-CDC and NSRR, the energy deposited near the outside edge of the pellet is the primary heat source for cladding melting, while the energy deposited in the interior of the fuel is not conducted to the cladding surface until after the maximum cladding surface temperature is reached. The effects of differences in fuel density can be taken into account by converting the energy deposition data to a volumetric basis. It was found that the failure threshold behavior of various test fuels could be considered in terms of peak energy deposition per unit volume of fuel at the fuel surface, a parameter that should be strongly related to cladding temperature. Figure 21 shows the failure behavior data obtained from the SPERT-CDC and NSRR tests when plotted in terms of fuel surface energy deposition per unit volume. Taking into account the uncertainty in the energy deposition determination of the NSRR data, the combined data indicate the existence of a single failure threshold. With the exception of the GEP-pellet rods, all other rods failed when the peak energy deposition

[a] SPERT is the acronym for Special Power Excursion Reactor Tests, the name given to test facilities at The Idāho National Engineering Laboratory. TREAT is the acronym for Transient REActor Tests, another INEL facility.

[b] NSRR stands for Nuclear Safety Research Reactor, a facility of the Japan Atomic Energy Research Institute. 


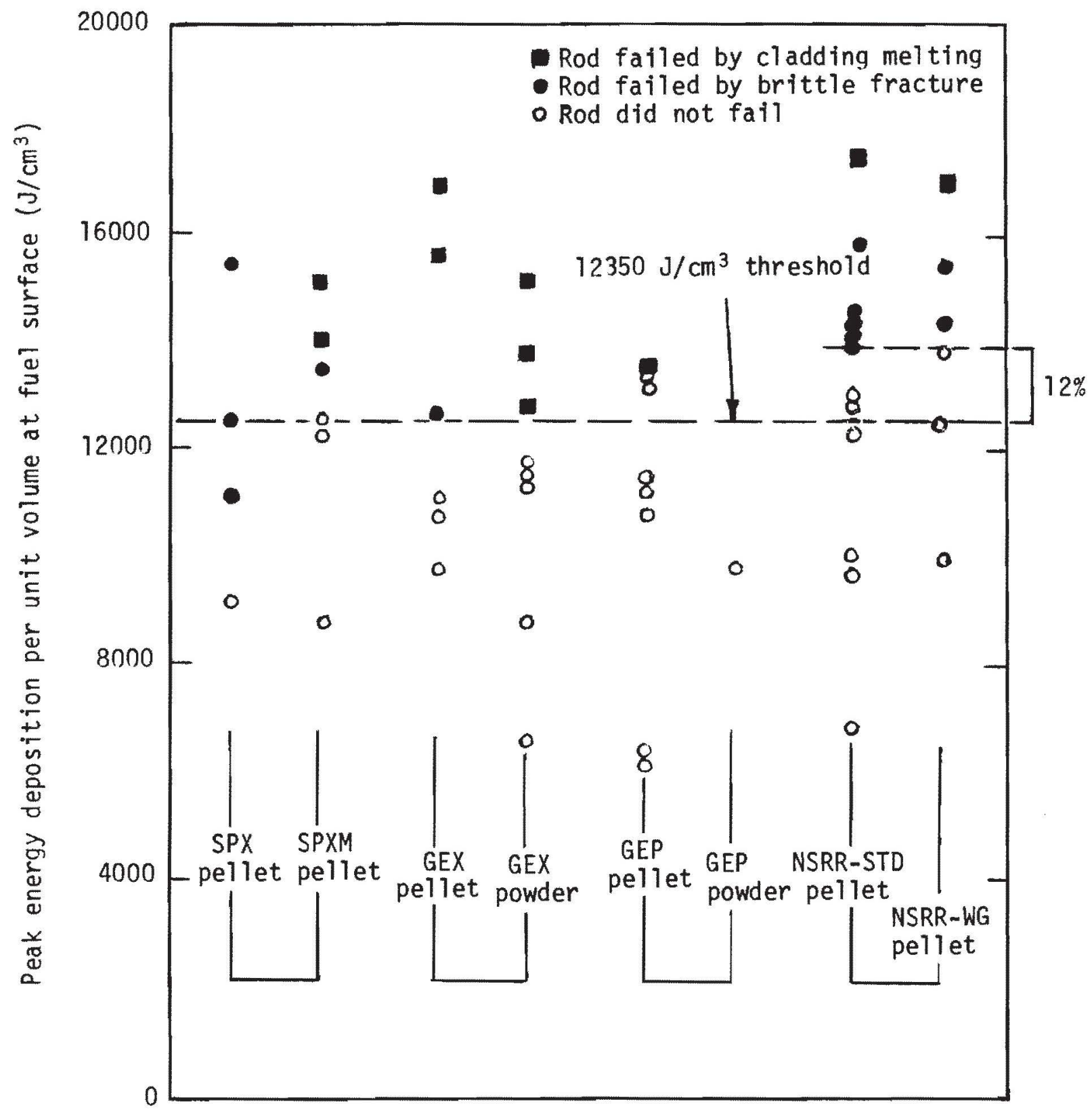

Fuel rod type

Fig, 21 Failure behavior of. CDC and NSRR test fuel rods as a function of pellet surface energy deposition per unit fuel volume. 
near the fuel surface exceeded $12.350 \times 10^{3} \mathrm{~J} / \mathrm{cm}^{3}\left(2950 \mathrm{cal} / \mathrm{cm}^{3}\right)$. Conformity to this rule should apply as long as there is fuel-cladding gap closure following the transient. When the RIA-ST-1, -2 , and -3 fuel density of $10.365 \mathrm{~g} / \mathrm{cm}^{3}$ is considered, the failure threshold becomes $1190 \mathrm{~J} / \mathrm{g}(284 \mathrm{cal} / \mathrm{g})$.

Figure 21 also provides information about the failure modes of the various fuel types. With the exception of the GEP rods, all pellet rods failed by brittle fracture at energy depositions near the theshold value. At slightly higher energy depositions, the failure mode changed to low pressure rupture due to weakening of the cladding as the melting temperature was approached (for all pellet rods except the SPX type). The failure mode of the SPX pellet rods is believed to have been influenced by their unusual dimensional characteristics which result in stronger pellet-cladding interaction and larger hending forces. Based only on this information, the failure of the RIA-ST, $9.70 \mathrm{~mm}$ OD test rods could be postulated to result from brittle fracture for energy depositions near the theshold value and low pressure rupture due to high temperature cladding weakening for slightly higher depositions. The high coolant system pressure of the PBF in-pile tube will have some effect on the low pressure cladding rupture failure mode. The nature of this effect is unknown at present. Small internal rod pressure increases were sufficient to cause cladding rupture in previous tests conducted at atmospheric pressure. For energy depositions greater than $1465 \mathrm{~J} / \mathrm{g}$ the failure mode observed in the SPERT-CDC tests was vigorous cladding rupture prior to melting probably due to internal $\mathrm{UO}_{2}$ vaporization pressure.

Figure 22 shows the maximum cladding surface data from the SPERT-CDC and NSRR data displayed as a function of peak energy deposition per unit volume at the fuel surface. With one exception, fuel rod failures occurred only when cladding temperatures exceeded a temperature of $2073 \mathrm{~K}, 25$ degrees below the melting point of zircaloy $(2098.2 \mathrm{~K})$. For this reason, $2073 \mathrm{~K}$, was chosen as the failure limit for the FRAP-T4 results discussed in Section 3.3 and illustrated by Figure 19. The excellent correlation between cladding temperature and rod failure can be expected because of the direct 


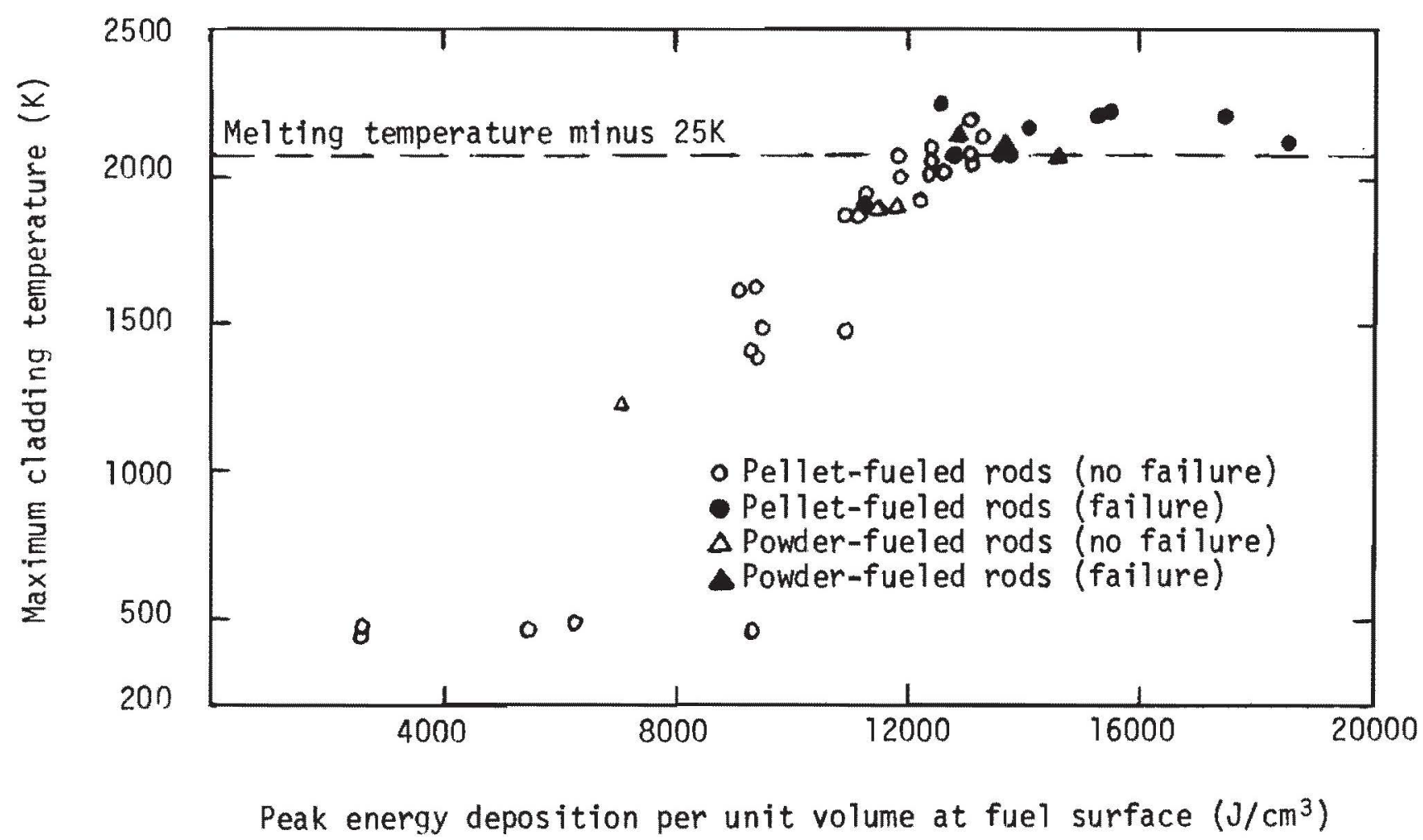

Fig. 22 Maximum cladding temperature as a function of pellet surface energy deposition per unit fuel volume for the CDC tests. 
relationship between fuel surface energy deposition and cladding temperature and the postulated existence of an energy deposition failure threshold.

The amount of energy deposition during a test transient also affected the consequences of failure in unirradiated $U_{2}$ fue $T$ rods. Increasing energy depositions resulted in more severe fuel rod damage and larger measured capsule pressures. The extent of metal-water reaction and conversion from nuclear-to-mechanical energy also increased. Cladding and fuel deformed both radially and axially. The radial deformation was directly related to thermal expansion of the fuel. Elongation of the cladding was apparently due to growth of the fuel stack following fuelcladding gap closure. Slippage between the cladding and the fuel was also observed.

Recent tests at the NSRR have also addressed the possible effects on rod failure of repetitive testing on the same fuel rod. These tests have not provided conclusive data yet but preliminary results indicate that the repetitive transients have little effect on failure threshold. Reduction of the fuel-water ratio through the use of flow shroud enclosures (no forced flow) caused a reduction in the failure threshold by about $10 \%$ in some tests at the NSRR. 


\section{CONCLUSIONS}

Thus $f a r$, this report has presented the results of several different analyses and a discussion of some previously obtained RIA test results. It is the purpose of this section to evaluate the information presented and arrive at experiment predictions for the RIA Scoping Test. First, test fuel rod energy as a function of PBF reactor core energy is predicted for the $9.70 \mathrm{~mm}$ OD fuel rods of phases RIA-ST-1, RIA-ST-2, and RIA-ST-3. The pellet surface energy deposition at which the $9.70 \mathrm{~mm}$ OD fue 1 rods are expected to fail and the expected mode of failure are predicted next. Finally, the mode of failure for the $10.73 \mathrm{~mm}$ on test fue 1 rods subjected to radially averaged energy depositions of 1990 and $2510 \mathrm{~J} / \mathrm{g}$ and the magnitudes of the expected failure-induced pressure pulses are predicted. The conclusions which have been drawn to make these predictions are based on the respective analyses and the SPERT, TREAT, and NSRR Test results.

The prediction of test fuel rod energy with respect to core energy is based on the results of the reactor physics calculations discussed in Section 3.1. Table III, in that section, provides the results of the calculations and thus the predictions. The radial fuel pellet surfaceto-average power factor is expected to be 1.076 .

The prediction of energy deposition fallure threshold and mode of failure for the $9.70 \mathrm{~mm}$ on fuel rods is based primarily on the results of the fuel rod behavior and cladding embrittlement analyses discussed in Sections 3.3 and 3.4. Previous RIA testing experience, such as that obtained in the SPERT-CDC and NSRR facilities, serves to direct and provide a comparison with the predictions.

From the results of the SPERT-CDC and NSRR Tests (discussed in Section 4), three principal conclusions can be drawn. First, a maximum cladding temperature reaching or exceeding $2073 \mathrm{~K}$ should result in cladding failure following a reactivity insertion transient. Second, the mode of failure should be either brittle fracture of the cladding due to 
excessive oxidation or pressure-induced rupture due to high temperature weakening of the cladding. Finally, for RIA-ST, $9.70 \mathrm{~mm}$ OD-type fuel rods, the baseline data indicate that the minimum energy deposition at the pellet surface resulting in rod failure should be $1190 \mathrm{~J} / \mathrm{g}(284 \mathrm{cal} / \mathrm{g})$ for transients initiated from ambient coolant conditions and no forced flow. The PBF-RIA tests will be performed with initial conditions of $538 \mathrm{~K}, 6.45 \mathrm{MPa}$, and $85 \mathrm{~cm}^{3} / \mathrm{s}$. The fuel enthalpy associated with this $240 \mathrm{~K}$ difference in initial temperature is equivalent to a pellet surface energy deposition of about $69 \mathrm{~J} / \mathrm{g}$. If the previous CDC and NSRR power transient tests had been run with the PBF-RIA test initial conditions, the observed failure threshold would be expected to drop to $1122 \mathrm{~J} / \mathrm{g}(268 \mathrm{cal} / \mathrm{g})$, neglecting the thermal-hydraulic effects of coolant flow and flow shrouding.

FRAP-T4 calculations showed that a pellet surface energy deposition of approximately $1035 \mathrm{~J} / \mathrm{g}(247 \mathrm{cal} / \mathrm{g})$ will result in a maximum cladding temperature of $2073 \mathrm{~K}$ for the $9.70 \mathrm{~mm}$ OD fuel rods. From the CDC-NSRR results it would be expected that this temperature will cause cladding failure. The cladding embrittlement analysis precludes brittle fracture as the mode of failure, indicating that the accumulation of oxygen into the zircaloy would not be sufficient after the $1035 \mathrm{~J} / \mathrm{g}$ energy deposition to make this failure mode probable. The expected failure mode, therefore, is rupture due to high temperature weakening of the cladding, and it should occur when the cladding temperature is at a maximum. The consequences of this mode of failure are expected to be minimal with only small pressure pulses generated.

The energy deposition threshold predicted from the analyses $(1035 \mathrm{~J} / \mathrm{g}$ ) is $87 \mathrm{~J} / \mathrm{g}(21 \mathrm{cal} / \mathrm{g})$ less than the $1122 \mathrm{~J} / \mathrm{g}$ of the previous RIA tests. It is believed that this discrepancy is a result of uncertainty in the complex transient heat transfer correlations of FRAP-T4 and possibly the influence of the PBF-RIA test flow shrouds. It should also be stated that uncertainty exists in the cladding embrittlement analysis because the temperatures considered were beyond the ranqe of reliability of the reaction layer correlation, and because the failure criteria were based on power-coolant-mismatch tests and not RIAs. The SPERT-CDC tests 
results indicate that the failure mode for the initial RIA-ST phases could be brittle fracture due to cladding oxidation. The presence of a flow shroud increases the time to cladding quench without greatly affecting the peak cladding temperature. This should result in a higher probability of cladding embrittlement failure.

The mode of failure for the $10.73 \mathrm{~mm}$ OD fuel rods used in phases RIA-ST-4 and RIA-ST-5 and the magnitudes of the pressure pulses expected in the coolant as a result of their failure are predicted based on the FRAP-T4 calculation performed, previous experience, and the pressure pulse analyses discussed in Section 3.5. Past RIA Tests have all indicated that for high energy depositions, above $1465 \mathrm{~J} / \mathrm{g}(350 \mathrm{cal} / \mathrm{g}) \mathrm{radi}-$ ally averaged, the failure mode is cladding rupture due to internal rod pressurization from $\mathrm{UO}_{2}$ vaporization. The FRAP-T4 calculation that was performed for the $2510 \mathrm{~J} / \mathrm{g}$ case indicates extensive $\mathrm{UO}_{2}$ vaporization, supporting the previously observed failure mode. Therefore, for radially averaged energy depositions at the power peak elevation of 1990 and $2510 \mathrm{~J} / \mathrm{g}$, the rod failure mode is predicted to be cladding rupture due to internal rod pressurization from fuel vaporization.

The $2510 \mathrm{~J} / \mathrm{g}$ energy deposition rod failure should result in a source coolant pressure of $25 \mathrm{MPa}$ with pressure doubling occurring at the top and bottom of the IPT. The pressure propagation back and forth through the IPT will give a maximum pressure of $35 \mathrm{MPa}$ with a rise time of $7 \mathrm{~ms}$. The $1990 \mathrm{~J} / \mathrm{g}$ deposition rod failure should result in a source pressure pulse of $24 \mathrm{MPa}$. Pressure doubling of $31.7 \mathrm{MPa}$ is predicted to occur at $7 \mathrm{~ms}$ after fuel dispersal.

To summarize:

(1) Table III of Section 3.1 provides the predictions of test rod energy as a function of PBF core energy. The radial fuel pellet surface-to-average factor is 1.076 .

(2) The energy deposition failure threshold for RIA-ST-1, RIA-ST-2, and RIA-ST-3 is predicted to be $1035 \mathrm{~J} / \mathrm{g}$, and the mode of 
failure is predicted to be pressure-induced rupture due to high temperature weakening of the cladding. The generated pressure pulses are expected to be minimal for these failures.

(3) The failure mode for the high energy phases, RIA-ST-4 and RIA-ST-5, is predicted to be internal pressure induced cladding rupture due to $\mathrm{UO}_{2}$ vaporization. The maximum dynamic pressures that will result are predicted to be 31.7 and $34.5 \mathrm{MPa}$, respectively, for the 1990 and $2510 \mathrm{~J} / \mathrm{g}$ radially averaged energy depositions.

The first three phases of the RIA Scoping Test were designed to experimentally determine the failure threshold and failure mode for the $9.70 \mathrm{~mm}$ OD fuel rods for Boiling Water Reactor hot startup conditions. The data obtained from these transients will be valuable in refining the analytical codes used to make these predictions. These data will point out deficiencies in the codes' abilities to characterize the RIA transient behavior, and they will identify additional areas of code development. The final phases of the Scoping Test will provide sufficient pressure pulse data to refine this calculation. 


\section{REFERENCES}

1. R. S. Semken, T. Inabe, Z. R. Martinson, Reactivity Initiated Accident Test Series RIA Scoping Test Experiment Operating Specification, TFBP-TR-217 (May 1978).

2. T. E. Young, Physics Calculations for RIA Scoping Test, EG\&G Idaho, Inc. Interoffice Correspondence, YNG-8-77 (October 1977).

3. R. S. Marsden, SCAMP Code Input Description, Mars-15-68 (May 1968).

4. K. R. Katsma et a1, RELAP4/MOD5 - A Computer Program for Transient Thermal-Hydraulic Analys is of Nuclear Reactors and Related Systems User's Manual, ANCR-NUREG-1335 (September 1976).

5. J. A. Dearien et al, FRAP-T4 A Computer Code for the Transient Analys is of Oxide Fuel Rods, TFBP-TR-237 (November 1977).

6. J. V. Cathcart et al, Zirconium Metal-Water Oxidation Kinetics IV, Reaction Rate Studies, ORNL/NUREG-17 (August 1977).

7. T. Fujishiro et a7, Light Water Reactor Fuel Response During Reactivity Initiated Accident Type Tests, TFBP-TR-246 (December 1977). 
APPENDIX A

RIA SCOPING TEST

RELAP4 MODEL DESCRIPTION 
APPENDIX A

\section{RIA SCOPING TEST RELAP4 MODEL DESCRIPTION}

The RELAP4 nodalization mode 1 is illustrated by Figure $A-1$. In the model, the RIA-ST test loop and in-pile tube are described by 59 fluid volumes connected by 63 flow junctions. There is a pump and heat exchanger in the 10op, and there are 5 stacked heat slabs attached to the fuel region fluid volumes which represent the fuel rod. Tables A-I and A-II list the fluid volume and flow junction data used in the analysis.

In the model, the in-pile tube consists of a downcomer through which coolant enters the lower plenum. The coolant then splits and $80 \%$ of the flow bypasses the fuel rod flow shroud. The remaining $20 \%$ passes up through the turbine flowmeters and inlet orifice and flows into the fuel rod region of the flow shroud. The two coolant paths converge again in the upper plenum and then exit the in-pile tube, flowing out into the RIA-ST test loop.

The rod axial power profile that was used in the RELAP analysis is shown in Table A-III. The $1350 \mathrm{~J} / \mathrm{g}$ pellet surface energy deposition transient was distributed to the fluid volumes of the model as the table indicates. In addition to the $1350 \mathrm{~J} / \mathrm{g}$ deposition, moderator heating was also deposited directly into the fuel region fluid volumes. A moderator heating rate of $21.8 \%$ of the transient energy deposition rate in the fuel rod was modeled. Total moderator heating was about $7.88 \mathrm{~kJ}$. The analysis consisted of $1 \mathrm{~s}$ of steady state calculation time followed by the transient. The total energy deposited into the fuel region fluid volumes was $446 \mathrm{~kJ}$. 


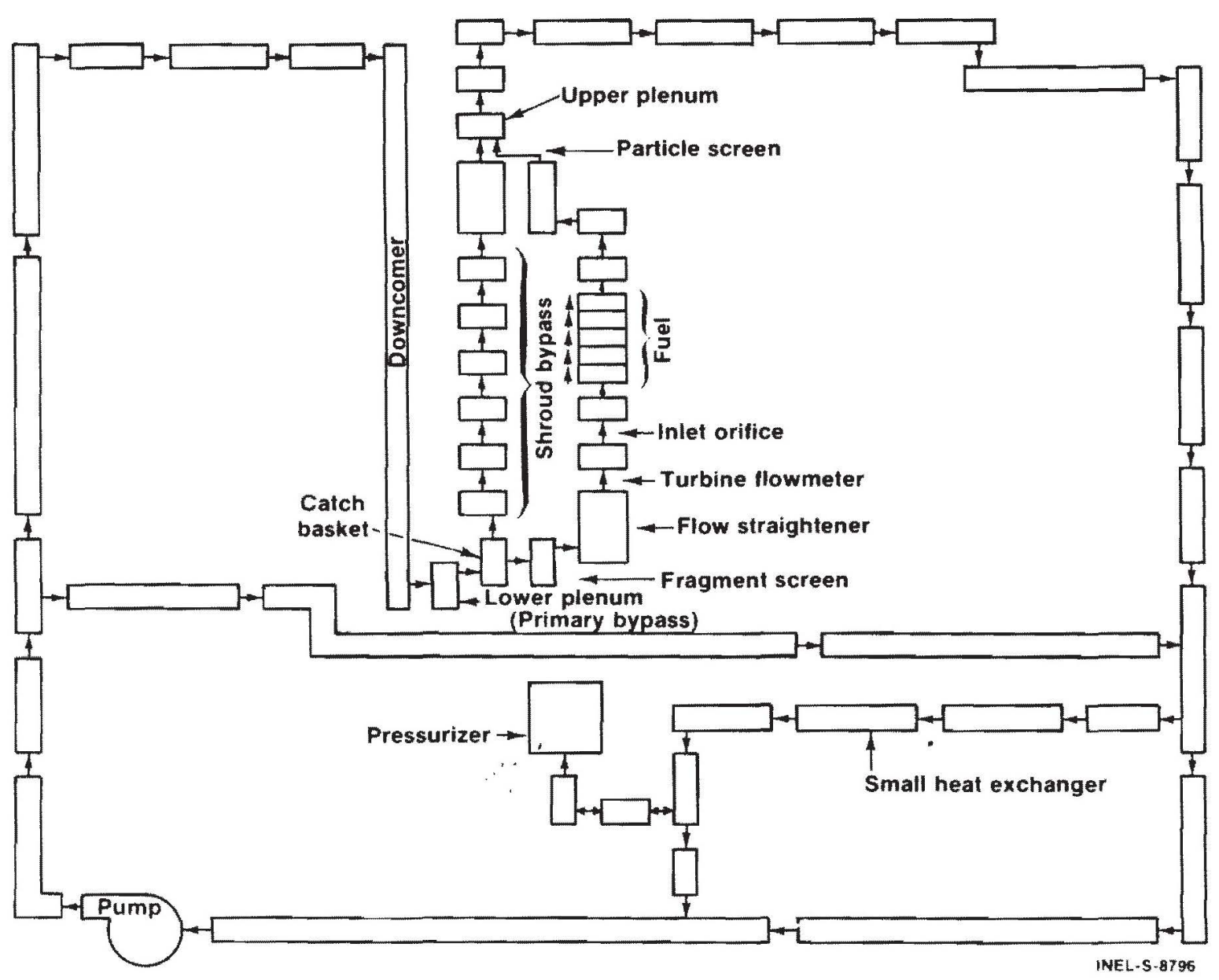

Fiq. A-1 RELAP transient model of the RIA-ST test loop. 
TABLE A-1

RELAP CONTROL VOLUME OATA USED IN RIA-ST-Y ANALYSIS

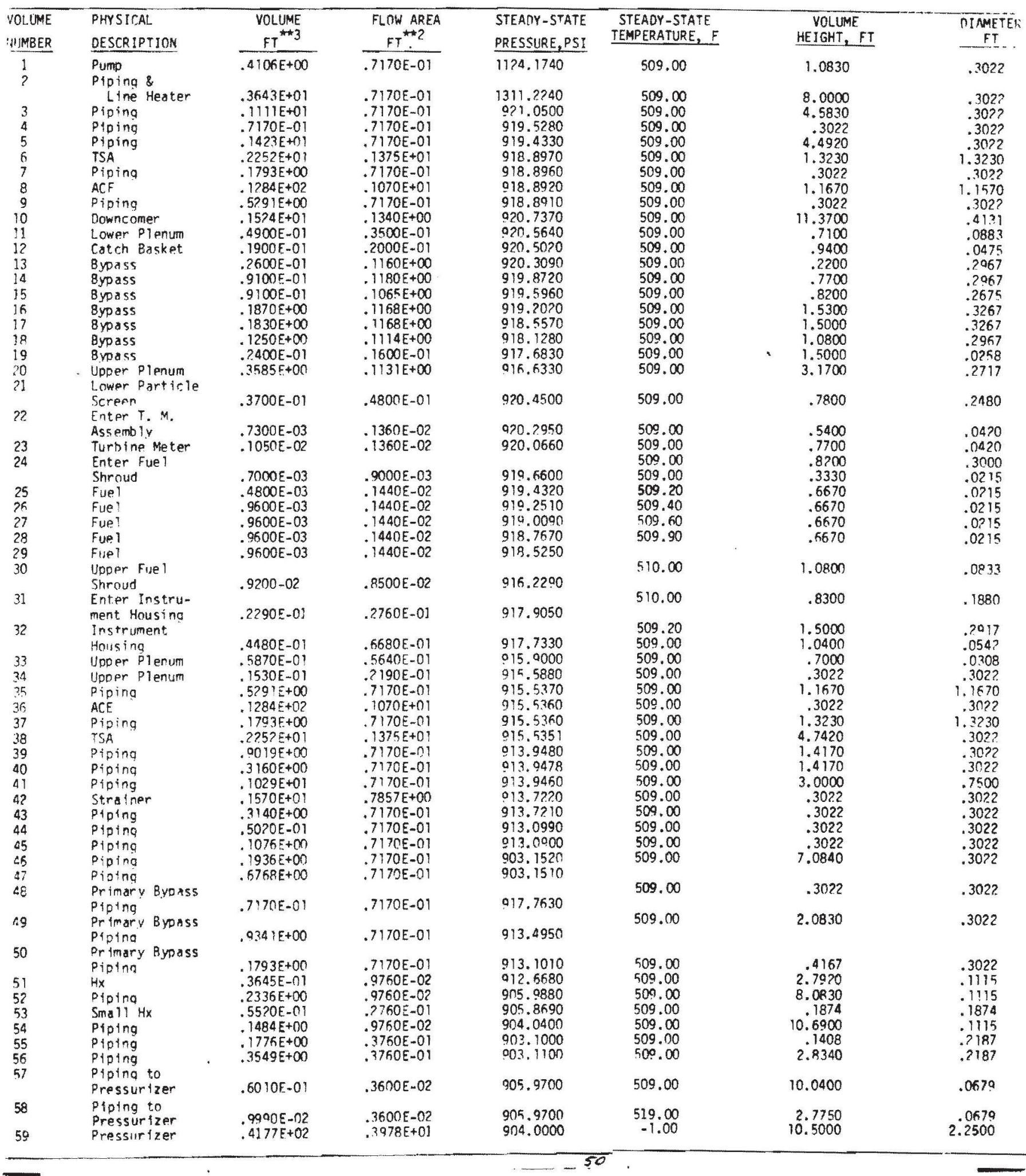


1 HOLLE

RELAPA JUNCTION DATA USED IN ST-1 ANALYSIS

\begin{tabular}{|c|c|c|c|c|}
\hline \multirow[b]{2}{*}{$\begin{array}{l}\text { JUACTION } \\
\text { NUMBER }\end{array}$} & \multirow[b]{2}{*}{$\begin{array}{l}\text { CONNECTING } \\
\text { VOLUMES } \\
\end{array}$} & \multirow[b]{2}{*}{$\begin{array}{l}\text { FLOW } \\
\text { LBM/SEC } \\
\end{array}$} & \multirow{2}{*}{$\begin{array}{l}\text { FORWARD FLOW } \\
\text { LOSS COEFFICIENT, } \\
\text { RF }\end{array}$} & REVERSE FLOW \\
\hline & & & & $\begin{array}{c}\text { LNSS COEFFICIENT, } \\
\mathrm{KR} \\
\end{array}$ \\
\hline I & 1 to 2 & 26.7400 & $.1004 E+03$ & $.1004 E+03$ \\
\hline 2 & 2 to 3 & 26.7400 & $.1085 E+04$ & $.1085 E+04$ \\
\hline 3 & 3 to 4 & 26.7400 & $.2090 \mathrm{E}+01$ & $.2000 \mathrm{E}+01$ \\
\hline 4 & 4 to 48 & 26.0090 & $.2500 E+00$ & $.2500 E+00$ \\
\hline 5 & 4 to 5 & .7310 & $.1000 E-0 ?$ & $.1000 E-01$ \\
\hline 6 & 5 to 6 & .7310 & $.1000 \mathrm{E}-01$ & $.1000 \mathrm{E}-01$ \\
\hline 7 & 6 to 7 & .7310 & $.1000 \mathrm{E}-01$ & $.1000 E-01$ \\
\hline 8 & 7 to 8 & .7310 & $.1000 \mathrm{E}-01$ & .1000 E-DI \\
\hline 9 & 8 to 9 & .7310 & $.1000 \mathrm{E}-01$ & $.1000 E-01$ \\
\hline 10 & $q$ to 10 & .7310 & $.1000 F-01$ & $.1000 \mathrm{E}-01$ \\
\hline 11 & $10 \tan 11$ & .7310 & $.3600 F+10$ & $.3600 E+00$ \\
\hline 12 & 11 to 12 & .7310 & $.1050 E+01$ & $.1050 F+01$ \\
\hline 13 & $12 \operatorname{tn} 13$ & .5650 & $.6300 E+00$ & . $6800 \mathrm{E}+0 \mathrm{O}$ \\
\hline 14 & 13 to 14 & .5850 & $.1420 E+01$ & $.1420 E+01$ \\
\hline 15 & 14 to 15 & .5850 & $.1250 E+01$ & $.1750 E+01$ \\
\hline 16 & 15 to 16 & .5850 & $.8900 E+00$ & $.8200 E+00$ \\
\hline 17 & 16 to 17 & .5850 & $.1000 E-01$ & $.10005-01$ \\
\hline 18 & 17 to 18 & .5850 & $.5900 E+00$ & $.5900 E+00$ \\
\hline 19 & 18 to 19 & .5850 & $.6000 E+00$ & $.6000 E \div 00$ \\
\hline 20 & 19 to 20 & .7285 & $.7400 E+00$ & $.7400 E+00$ \\
\hline 21 & 20 to 21 & .1460 & $.4000 E-01$ & $.4000 \mathrm{E}-01$ \\
\hline 22 & 21 to 22 & .1460 & $.4500 \mathrm{E}+00$ & $.4500 E+00$ \\
\hline 23 & 22 to 23 & .1460 & 0 & 0 \\
\hline 24 & 23 to 24 & .1460 & $.3100 \mathrm{E}+00$ & $.3100 \mathrm{~F}+00$ \\
\hline 25 & 24 to 25 & .1460 & $.1400 E+00$ & $.1400 E+n 0$ \\
\hline 26 & 25 to 76 & .1450 & $.1000 E-01$ & $.1000 E-01$ \\
\hline 27 & 26 to $? ?$ & .1460 & . $1000 E-0 ?$ & $.1000 E-01$ \\
\hline 28 & 27 to 28 & .1460 & $.2000 \mathrm{E}-01$ & $.2000 \mathrm{E}-01$ \\
\hline 29 & 28 to 29 & .1460 & $.2000 E-01$ & $.2000 E-01$ \\
\hline 30 & 29 to 30 & .1460 & $.6900 \mathrm{~F}+00$ & $.6900 E+00$ \\
\hline 31 & 30 to 31 & .1460 & $.4800 F+00$ & $\triangle 800 E+00$ \\
\hline 32 & 31 to 32 & .1460 & $.1240 E+01$ & $.1250 E+01$ \\
\hline 33 & 32 to 19 & .1435 & $.1870 E+01$ & $.1870 E+01$ \\
\hline 34 & 32 to 20 & .0025 & $.2100 E+00$ & $.2100 \mathrm{E}+00$ \\
\hline 35 & 20 to 33 & .7370 & $.1180 E+01$ & $.1180 E+01$ \\
\hline 36 & 33 to 34 & .7310 & $.8300 E+00$ & $.200 \mathrm{~F}+00$ \\
\hline 37 & 34 to 35 & .7310 & $.4500 E+00$ & $.4500 \mathrm{E}+00$ \\
\hline 38 & 35 to 36 & .7310 & $.1000 E-01$ & $.1000 \mathrm{E}-01$ \\
\hline 39 & 36 to 37 & .7310 & $.1000 E_{-01}$ & $.1000 E-01$ \\
\hline 40 & 37 to 38 & .7310 & $.1000 E-01$ & INOOE-OI \\
\hline 41 & $38+039$ & .7370 & $.1000 E-01$ & INONE -01 \\
\hline $4 ?$ & 39 to 40 & .7310 & IOONE $=\cap 1$ & $.1000 \mathrm{E}-01$ \\
\hline 43 & 40 to 41 & .7310 & $1000 \mathrm{~F}-01$ & $.100 n F_{-n 1}$ \\
\hline 44 & 41 to 42 & .7310 & $.1000 \mathrm{E}-\mathrm{OI}$ & $.1000 \mathrm{E}-101$ \\
\hline 45 & 42 to 43 & .7310 & $.1000 E-01$ & $.1000 \mathrm{E}-01$ \\
\hline 46 & 43 to 44 & .7310 & InOOE-01 & .1000 E-01 \\
\hline 47 & 44 to 45 & 75.7400 & $.1450 E+00$ & $.450 E+100$ \\
\hline 48 & 45 to 46 & 25.7400 & $.3462 \mathrm{E}+02$ & $.346 ? E+02$ \\
\hline 49 & 46 to 47 & 25.7400 & $.3570 \mathrm{E}+01$ & $.3570 E+\cap 1$ \\
\hline 50 & 47 to 1 & 26.7400 & 0 & 0. \\
\hline 51 & 48 to 49 & 25.0090 & $.1100 E+01$ &, $1100 E+01$ \\
\hline 52 & 49 to 50 & 25.0090 & $.1000 \mathrm{~F}-01$ & $.1000 E-01$ \\
\hline 53 & 50 to 44 & 26.0090 & $.1000 E-01$ & $.1000 E_{-01}$ \\
\hline 54 & 44 to 51 & 1.0000 & $.1000 E-01$ & $.1000 \mathrm{E}-01$ \\
\hline 55 & 51 to 52 & 1.0000 & $.1000 E-01$ & $1000 \mathrm{E}-01$ \\
\hline 56 & 52 to 53 & 1.0000 & $.1000 \mathrm{E}-01$ & .1000 E-01 \\
\hline 57 & 53 to 54 & 1.0000 & $.1000 \mathrm{E}-0 \mathrm{I}$ & $.1000 E-01$ \\
\hline 58 & 54 to 55 & 1.0000 & $.1000 E-01$ & $.1000 E-0^{1}$ \\
\hline 59 & 55 to 56 & 1.0000 & $.1000 E-01$ & $.1000 E-01$ \\
\hline 60 & 56 to 47 & 1.0000 & $.10005-01$ & $.1000 E-01$ \\
\hline 51 & 55 to 57 & 0.0000 & $.6000 E-01$ & $.6000 E_{-01}$ \\
\hline 62 & 57 to 58 & 0.0000 & $.2500 E+00$ & $.2500 \mathrm{E}+0 \mathrm{O}$ \\
\hline 63 & 58 to 59 & 0.0000 & $.2500 E+00$ & $.2500 E+00$ \\
\hline
\end{tabular}




\section{TABLE A-III}

THE ROD AXIAL POWER PROFILE USED IN THE RIA SCOPING TEST RELAP4 ANALYSES

Fuel Axial Location (ft.)

0 to 0.333

0.333 to 1.0

1.0 to 1.667

1.667 to 2.334

2.334 to 3.0
Normalized Power

0.211

0.789

1.0

0.866

0.490 
APPENDIX B

RIA SCOPING TEST

FRAP - T4 CODE INPUT SUMMARY 


\section{APPENDIX B}

FRAP-T4 INPUT PARAMETERS CORRELATIONS AND MODELING OPTIONS

The response of the RIA Scoping Test fuel rods was analyzed using the FRAP-T4 computer code. The FRAP-T4 code is a transient fuel rod thermal analysis code used to solve for the response of a fuel rod under various accident conditions. Table B-I presents a listing of the input parameters, correlations, and modeling options used in the final FRAP-T4 fuel analyses. Table B-II lists the normalized peak-to-average axial power profile, and Table B-III lists the normalized peak-to-average radial power profile used in the analyses. Table B-IV is an input summary for the FRAP-T4 analyses. 
INPUT PARAMETERS, CORRELATIONS AND MODELING OPTIONS USED

IN THE FRAP-T4 CALCULATIONS FOR RIA-ST

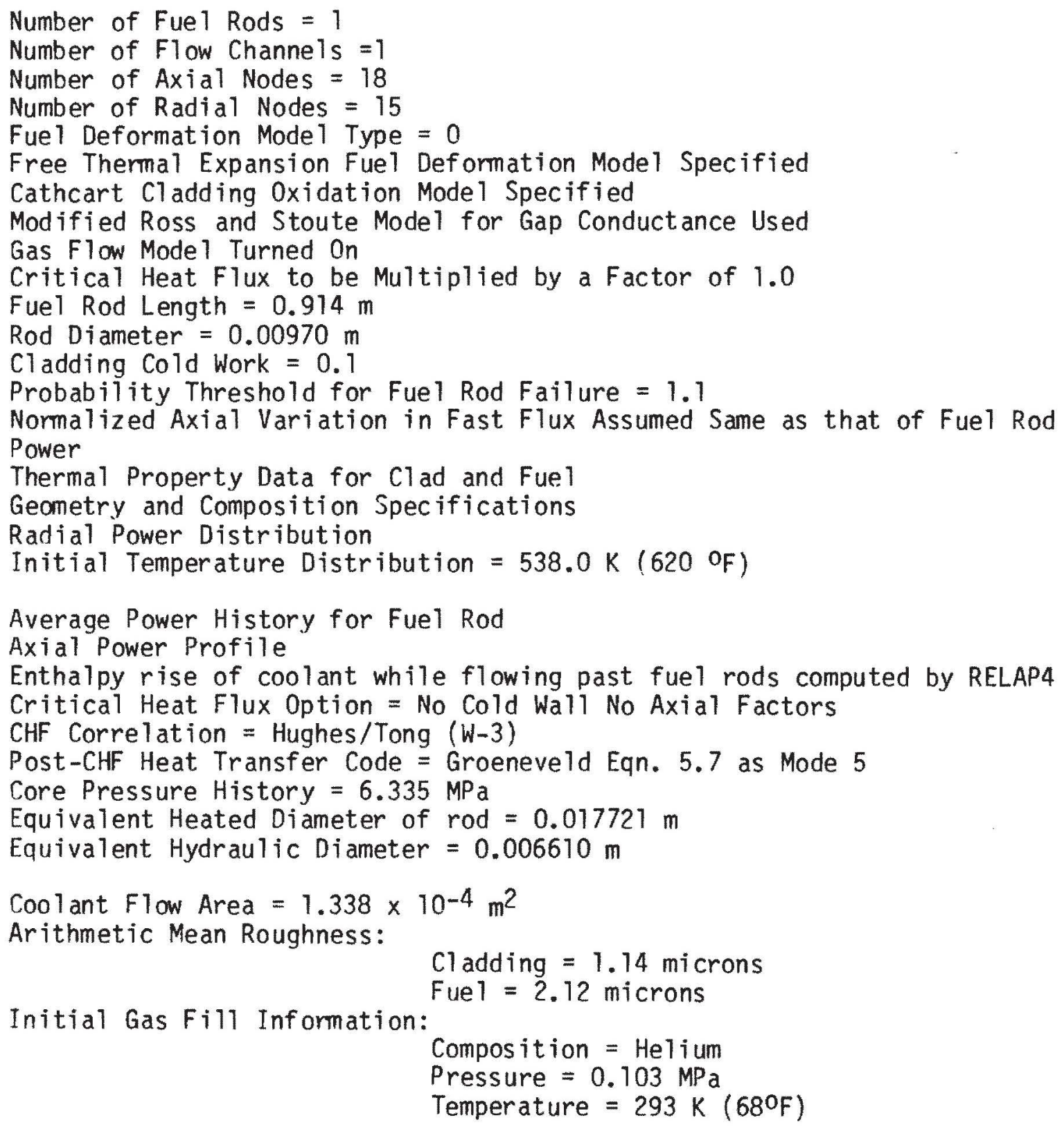


TABLE B-II

NORMALIZED PEAK TO AVERAGE AXIAL POWER PROFILE

Distance from Bottom of

Fuel Pellet Stack (m)

0.0254

0.0762

0.1270

0.1778

0.2286

0.2794

0.3302

0.3810

0.4318

0.4826

0.5334

0.5842

0.6350

0.6858

0.7366

0.7874

0.8382

0.8890
Norma 7 ized

Value

0.54

0.69

0.85

1.03

1.13

1.24

1.30

1.34

1.36

1.32

1.28

1.20

1.11

1.00

0.87

0.72

0.58

0.44 
TABLE B-III

NORMALIZED PEAK TO AVERAGE RADIAL POWER PROFILE

\begin{tabular}{lc}
\hline RADIUS $(\mathrm{m})$ & Normalized Value \\
\hline .000187 & 0.942 \\
.000561 & 0.943 \\
.000935 & 0.946 \\
.001309 & 0.951 \\
.001683 & 0.957 \\
.002058 & 0.964 \\
.002432 & 0.975 \\
.002806 & 0.992 \\
.003180 & 1.009 \\
.003554 & 1.030 \\
& 1.063 \\
\hline
\end{tabular}


TABLE B-IV

FRAP-T CODE INPUT SUMMARY

\begin{tabular}{|c|c|c|c|}
\hline & & $\begin{array}{l}9.70-m m \\
\text { OD Fuel Rod }\end{array}$ & $\begin{array}{l}\text { 10.7-rmm } \\
\text { OD Fuel Rod }\end{array}$ \\
\hline \multirow[t]{10}{*}{ Fuel Region } & Active Length (m) & 0.9144 & 0.9144 \\
\hline & Material & $\mathrm{UO}_{2}$ & $\mathrm{UO}_{2}$ \\
\hline & Enrichment $(\%)$ & 5.7 & $20^{6}$ \\
\hline & Pellet Height $(\mathrm{mm})$ & 15.2 & 15.49 \\
\hline & Pellet Diameter (mm) & 8.24 & 9.3 \\
\hline & Pellet Shoulder Radius (mm) & 3.3 & 3.1 \\
\hline & Dish Depth $(\mathrm{mm})$ & 0.343 & 0.33 \\
\hline & Density $\left(\mathrm{kg} / \mathrm{m}^{3}\right)$ & 10083 & 10276 \\
\hline & Theoretic Density $(\%)$ & 94.5 & 93 \\
\hline & RMS Roughness & 2.12 & 2.12 \\
\hline \multirow[t]{4}{*}{ Cladding Region } & Material & Zircaloy 4 & $\mathrm{Zr} \cdot 4$ \\
\hline & Cladding $10(\mathrm{~mm})$ & 8.42 & 9.51 \\
\hline & Cladding OD (mm) & 9.70 & 10.73 \\
\hline & RMS Roughnes & 1.14 & 1.14 \\
\hline \multirow[t]{7}{*}{ Plenum Region } & Gas Quantity (moles of $\mathrm{He}$ ) & 0.000282 & 0.0103 \\
\hline & Plenum Volume $\left(\mathrm{m}^{3}\right)$ & 2290 & 6720 \\
\hline & Gas Pressure (MPa) & 0.1034 & 2.6 \\
\hline & Spring Length (mm) & 50.8 & 50.8 \\
\hline & Spring Coil OD (mm) & 8.23 & 9.02 \\
\hline & Sprinq Wire Diameter (mm) & 1.02 & 1.02 \\
\hline & Number of Spring Coils & 17 & 17 \\
\hline \multirow[t]{3}{*}{ Flow Shroud } & Coolant Flow Area $\left(\mathrm{mm}^{2}\right)$ & 133.8 & 118.5 \\
\hline & Hydraulic Diameter (mm) & 6.61 & 5.58 \\
\hline & $\begin{array}{l}\text { Equivalent Heated Dia- } \\
\text { meter }(\mathrm{mm})\end{array}$ & 17.72 & 14.1 \\
\hline
\end{tabular}

